\title{
Comparison of Stellite coatings on low carbon steel produced by CGS and HVOF spraying
}

Rajab Ali Seraj ${ }^{1}$, Amir Abdollah-zadeh ${ }^{1, *}$, Sergi Dosta ${ }^{2, *}$, Hamid Assadi ${ }^{3}$, Irene Garcia Cano $^{2}$

${ }^{1}$ Department of Materials Engineering, Tarbiat Modares University, Tehran, Iran

${ }^{2}$ Thermal Spray Centre, Department of Materials Science and Engineering, Universitat de Barcelona, Barcelona, Spain

${ }^{3}$ Brunel Centre for Advanced Solidification Technology (BCAST), Brunel University London, UK

* Corresponding authors

Tel./fax: +98 21 88005040, E-mail: zadeh@modares.ac.ir (A. Abdollah-zadeh)

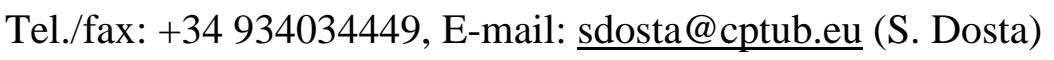




\section{Abstract}

Stellite alloys are of great interest in industries due to a unique combination of high temperature mechanical strength, outstanding wear and corrosion resistance. Different thermal spraying processes are used for deposition of stellite alloys on industrial components. However, the investigations on the structure-property relationship of these alloys produced via different deposition process are limited. This study focuses on the microstructure, oxidation, and tribo-mechanical properties of Stellite 21 deposited by cold gas spraying (CGS) and high velocity oxy-fuel (HVOF) process on a low carbon steel substrate. The coating crosssection was characterized by SEM and optical microscopy. The coatings were further characterised by using nanoindentation, adhesion, and ball-on-disk wear tests. Moreover, XRD tests were run on the powder and the coatings to reveal possible phase transformation during spraying, as well as during wear and oxidation tests. The results showed no phase transformation in the as-sprayed CGS coating, besides higher values of porosity and oxide phase in the HVOF coating. However, an fcc-to-hcp phase transformation occurs at the surface layer of both types of coating during the ball-on-disk wear test. The presence of continuous oxide networks in HVOF coatings leads to delamination during the wear test. Overall, the CGS Stellite 21 coatings exhibit better performance than HVOF coatings in wear and oxidation tests. 
Keywords: Stellite 21, Cold gas spraying, HVOF, Phase transformation, Wear test, Oxidation test.

\section{Introduction}

Tribological properties of cobalt-base alloys particularly at high temperatures make them a suitable option for aerospace, automotive and power industries [13]. The excellent tribological properties of cobalt-base alloys, such as Stellite ${ }^{\circledR}$, including remarkable galling resistance, allow them to withstand higher contact pressures than other metal alloys [1]. The main reason for their superior galling resistance comes from the martensitic phase transformation $(\gamma \rightarrow \varepsilon)$ [4-6], attributed to the low stacking fault energy (SFE) of cobalt-base alloys. Also the presence of residual $\gamma$ phase hinders the dislocation movement which increases the capability of work hardening and the galling wear resistance [5]. However, by increasing the amount of the alloying elements with higher stacking fault energy such as $\mathrm{Fe}$, the galling resistance of this alloy is diminished considerably [7-9].

Stellite alloys are deposited by different liquid state deposition techniques like welding [10-12], thermal spraying [8,9,13], supersonic laser deposition [14], and solid-state processes including friction surfacing [15] and explosive welding [16]. Different process leads to different tribomechanical and structure-property [6, 17]. The chemical composition of the coating is changed due to the substrate dilution during the welding of stellite alloys. So, the phase transformation 
capability and galling resistance of the deposited layer are less than those of the original alloy [9]. Moreover, multi-layer deposition or low heat input techniques (e.g. cold metal transfer welding process) are suggested for diminishing the dilution of the coating $[10,18]$. The multi-layer technique increases the cost and the time of deposition. In cold metal transfer welding process, tensile residual stress is developed in the coatings, and underbead cracks are observed on the stellite alloy deposited on heat treated steel substrates [10]. It means that hardfacing of heat treated steel by liquid state process is impossible even with low heat input $[7,10]$. The limitation of explosive welding from the viewpoint of safety regulations $[19,20]$ and also friction surfacing applicability only for simple flat geometries $[15,21]$ compel the researchers to use new methods. Therefore, thermal spray methods are suggested and used by different authors [22-26].

The thermally sprayed coatings are more beneficial from the stress point of view rather than welded overlay coating [27]. They are commonly used in different industries to deposit a coating with superior properties in various applications, e.g. in pump parts, valves, impellers, shafts and journal bearings [28, 29]. The coating application should be considered when the spraying technique is selected. Cold Gas Spray (CGS) and High Velocity Oxy-Fuel (HVOF) are two important thermal spraying methods, which can provide an attractive combination of properties in industrial components. However, the lamellar structure of HVOF coating, the presence of oxides decreases the deposited layer properties rather 
than those of the corresponding bulk material $[30,31]$. In such cases, subsequent treatments were applied in order to modify the microstructure of sprayed layer $[31,32]$.

On the other side, the low temperature of CGS leads to oxide-free coatings with excellent mechanical and corrosion properties in comparison with the HVOF method in which thermal effect is dominant [33]. In CGS, the powder particles are injected into the high pressure gas stream and accelerated toward a substrate. The particles' impact velocities of up to $1200 \mathrm{~m} \cdot \mathrm{s}^{-1}$ depending on the process parameters can be achived $[34,35]$. The bonding between the particle and the substrate establishes by adiabatic shear instability, which is the predominant bonding mechanism [36]. Due to the lower temperature of the gas in CGS than the conventional thermal spray methods, the particles preserve their composition, and no oxidation occurs during the deposition [37]. The low porosity coating along with the highly deformed particles arising from cold spraying process improve the coating properties significantly. The wear and microstructural evolution of CGS sprayed stellite alloys were reported by different authors. Cinca et al. $[22,38]$ showed that a dense Stellite- 6 coating with good wear resistance is achievable by CGS. In addition, cold spraying of the Stellite-based coating with promising properties in terms of microstructure compactness and coating hardness on a steel substrate is reported [39]. 
The mechanical properties and tribological performance of HVOF sprayed stellite alloys have been investigated by different authors [31, 40-44]. The wear mechanism of HVOF sprayed stellite alloys were investigated in detail by some authors $[28,45,46]$. Three main mechanism including of HVOF coating were proposed by them including: abrasive wear due to the significant soft mating material than the other, adhesive wear comes from the formation of microweld between the mating surface and brittle delamination resulting from the continues oxide layers between the splats. In spite of in-depth knowledge about the wear and oxidation of HVOF-sprayed stellite alloys [47, 48], there are limited investigations that compare the microstructure, tribomechanical and oxidation behavior of this alloy produced by two different manufacturing processes of CGS and HVOF. The current study focuses on the effect of deposition process on the Stellite 21 coating properties. For this purpose, Stellite 21 powder is deposited by both CGS and HVOF on low carbon steel substrates. The microstructure, mechanical, tribological and oxidation behaviors of the coatings are evaluated and compared.

\section{Experimental procedures}

In this study, a spherical morphology powder (Stelloric 1388 F0, ORIC Company, France) with the chemical composition of Stellite 21 was used. The chemical composition of the feedstock (in wt.\%) was $28 \mathrm{Cr}, 5.5 \mathrm{Mo}, 2.5 \mathrm{Ni}, 0.3$ C, $1 \mathrm{Si}, \mathrm{Fe}<2, \mathrm{~W}<0.5$, and balance Cobalt. AISI 1020 low carbon steel plate of 
$20 \times 50 \times 4 \mathrm{~mm}^{3}$ was used as substrate. The substrate was sandblasted by alumina grit 24 and then cleaned by acetone. The deposition was performed using KINETICS $₫ 4000$ (Cold Gas Technology, Ampfing, Germany) with nitrogen as process gas. In the CGS method, the maximum operating pressure (40bar) and temperature $\left(800^{\circ} \mathrm{C}\right)$ of the process gas were used. One-layer spraying performed at $10 \mathrm{~mm}$ stand-off distance and $100 \mathrm{~mm} \cdot \mathrm{s}^{-1}$ nozzle traverse speed. The nozzle was moved $1.5 \mathrm{~mm}$ in each pass to achieve a uniform coating. These parameters were selected according to our previous work to achieve a coating with the best adhesion and lowest porosity [49]. For HVOF, sulzer HVOF equipment Diamond Jet Hybrid (Winterthur, Switzerland) with DJH 2600 head that operates with hydrogen plus oxygen plus air mixture was used. The compressed air was used to cool down the substrate during and after the process. The HVOF process parameters as denoted in Table 1 were selected according to a previous work [50]. The roughness of the as-sprayed coatings were evaluated by rugosimeter SJ-210 (Mitutoyo) equipment.

The as-sprayed samples were cut and mounted in the resin. The mounted samples were prepared in accordance with the ASTM E3-95 and subsequently grinded on emery paper $(120,240,600,1200$ grit) and polished by 6 and $1 \mu \mathrm{m}$ monocrystalline diamond suspensions, respectively. Nital 5\% and $\mathrm{HCl}+\mathrm{H}_{2} \mathrm{O}_{2}$ were used as etchant solutions for the substrate and the coating, respectively. The polished cross-sections were investigated by optical and scanning electron 
microscopes to find the effect of spraying method on the coatings microstructure, the amount of porosity and coating integrity. The thickness of the coatings was measured on 200x magnified OM micrographs using image analysis software. The images were obtained along the coating cross-section and the average of 5 measurements was reported. Also the average value of the coatings porosity on 1000x magnification at 20 different areas was reported.

Vickers microhardness profile measurement was carried out on the cross-section of the coating. This measurement was repeated in three lines and the average value of them is reported. The distance of $100 \mu \mathrm{m}$ was selected between the indentations to avoid a mutual influence of indented points to the results. The load of $100 \mathrm{grf}$ was applied for $15 \mathrm{~s}$. Micromechanical properties of single splats consisting of CGS and HVOF coating cross-sections were investigated by nanoindentation equipment (Nano Indenter XP) with Berkovich triangular pyramid indenter. The indentations were applied in the middle of splat in the CGS and HVOF sprayed samples. The maximum load of $5 \mathrm{grf}$ was applied for $10 \mathrm{~s}$ in each indentation. Indenter calibration, measurement procedures and analysis of the load-penetration data were performed following standard ISO 14577. The Young modulus and the hardness of the samples were determined using the Oliver-Pharr method. The average of 10 measurements of the hardness $(\mathrm{H})$ and elastic modulus (E) was reported in nanoindentation tests. The distance of $40 \mu \mathrm{m}$ was selected between the indentations. 
Carbon steel cylinders (55 $\mathrm{mm}$ thick and $25 \mathrm{~mm}$ in diameter) were deposited for measuring the coatings adhesion-strength according to the ASTM C633-13. The coated cylinders were bonded to the same cylinder by a high strength glue. HTK ULTRA BOND ${ }^{\circledR} 100$ glue was used for adhesion test sample preparation. The bonded cylinders were placed under increasing tensile load using a constant rate of $0.01 \mathrm{~mm} \cdot \mathrm{s}^{-1}$ until fracture. The fracture load was divided by the cross-section area of the specimens to calculate their adhesion strength. Fracture surfaces were examined by SEM to distinguish the failure mode including internal failure (cohesive failure), interface failure (adhesive failure) and/or glue failure.

The sliding ball-on-disk (BoD) wear tests were performed in accordance with the ASTM G99-05 standard at room temperature $\left(\approx 25^{\circ} \mathrm{C}\right.$ and $<20 \%$ relative humidity). The surface of the as-sprayed sample was prepared to $0.8 \mu \mathrm{m}$ surface roughness before the test. $10 \mathrm{~mm}$ diameter $\mathrm{WC}$ balls were employed as counterparts. A constant normal load of $15 \mathrm{~N}$ was applied to the WC counterpart which was pressed against the prepared surface of the coating for $1000 \mathrm{~m}$ sliding distance. The wear track and debris were investigated by SEM. Also, the friction coefficient of the samples was calculated and reported. Confocal laser microscopy (Leica TSE-SE) was used to compute the lost volume and recreate the coatings wear track.

Isothermal oxidation behavior was investigated by exposing the coatings at $900^{\circ} \mathrm{C}$ for $144 \mathrm{~h}$ in air atmosphere. The surface of the samples was grinded with 1200 
grit $\mathrm{SiC}$ paper, and the edge of the samples was covered with high-temperature cement to avoid the substrate-coating interface oxidation. The samples were furnace cooled to room temperature. The morphology of the oxidized surface was investigated by SEM.

Phase identification was performed by $\mathrm{X}$-ray diffraction analysis with $\mathrm{Cu}-\mathrm{K} \alpha$ radiation (X-ray tube operated at $40 \mathrm{kV}$ and $40 \mathrm{~mA}$ ). The angular range over a $20^{\circ} \leq 2 \theta \leq 100^{\circ}$ were used to achieve the patterns. The measurements were conducted with $0.017^{\circ}$ and $50 \mathrm{~s} / \mathrm{step}$ step size and dwell time.

\section{Results and Discussion}

\subsection{Powder characterization}

The spherical morphology of feedstock produced by gas atomization process is represented in Fig. 1a. There are few satellites, which are typical of the gas atomizing process $[6,51]$. The optical micrograph of single particles' crosssection is shown in Fig. 1b. The feedstock particles show a Gaussian distribution; where, $\mathrm{d}_{\text {mean }}=35 \mu \mathrm{m}, \mathrm{d}_{10}=10 \mu \mathrm{m}$, and $\mathrm{d}_{90}=53 \mu \mathrm{m}$., measured by laser diffraction particle size analyzer (Fig. 1c). The particle size distribution influences the corresponding properties of thermal sprayed coatings and should be optimized for each process [52-54]. The normal range of particle sizes required for different thermal spray processes is related to the process characteristics and varied from $5 \mu \mathrm{m}$ to about $120 \mu \mathrm{m}$ [55]. The outcome of this argument is that it is better to use special particle size distributions of powder for each process, but this is more 
expensive. So in this study, the same powder particles size distribution was used for both CGS and HVOF.

\subsection{Coatings' Surface morphology}

Fig. 2 shows the as-sprayed surface morphology of CGS and HVOF coatings, which was taken by SEM. The spherical morphology of the bonded particle and metallic jets around it in CGS is represented by white arrow in Fig. 2c. The HVOF sprayed coating is composed of flattened splats, originating from high velocity impact of molten droplets. So, the initial morphology of the particles is not preserved in HVOF sample, and its surface roughness is lower than in CGS sample (Table 2).

\subsection{Coatings' microstructure}

The deposits' cross-section is represented in Fig. 3. The thicknesses of CGS and HVOF coatings are about $225 \mu \mathrm{m}$ and $250 \mu \mathrm{m}$, respectively. The mechanical interlocking of CGS coating to the substrate is visible in Fig. 3c. As shown in Figs. 4a and c, CGS coating has the same microstructure as the feedstock, and exhibits the dendritic structure. However, flattened appearance of the dendrites in the coating comparing to primary dendrites of the feedstock indicates considerable deformation of the powder particles during CGS (Figs. 4c and 1b). Due to the very fine microstructure of HVOF sprayed coating caused by higher cooling rate, the microstructure of this coating is not revealed by the same etching procedure (Figs. $4 \mathrm{~b}$ and d). The EDS analysis of the coatings' cross-section 
showed the concentration of oxygen in HVOF sample (Table 2). The higher value of oxygen in HVOF than in CGS indicates the formation of oxides during HVOF process $[27,28]$. The overall content of porosity in the coatings is calculated by image analysis and reported in Table 2 . The CGS coating exhibits a low level of porosity. Despite the high-temperature strength and high critical velocity of Cobase alloys [22], the lower amount of porosity of CGS coating is attributed to the particles' higher impact velocity and the hammering effect of subsequent particles on the surface of the coating. In HVOF, a dense coatings composed of well-flattened splats containing up to $6.1 \%$ oxide phase are produced. Highmagnification micrograph (Fig. 4d) reveals some cracks and interlamellar porosity. Despite the higher temperature of the particles upon impact, the large pores are created between the flattened droplets by the gas porosity phenomenon and also the shrinkage porosity produces small pores within the flattened particles [55-57]. The porosity creates poor coating cohesion and allows for higher wear and corrosion rates [55]. In CGS, spraying below the melting point of the particles prevents solidification shrinkage and gas porosity in the coating [58], leading to the lower porosity of the coating at optimized process parameters.

In Figs. $4 \mathrm{~b}$ and $\mathrm{d}$, the dark gray, elongated phase that appear as strings in the coating cross section, parallel to the substrate represents the oxide layer between the splats, which are produced by particle/atmosphere interaction and/or heating of the coating surface during deposition $[28,51,55]$. Porosity is another important 
coating feature which is seen as black phase in Fig. 4b. HVOF coating possesses well flattened and bonded lamellae. Sufficient plastic deformation experienced by the molten particles upon impact leads to a dense layer. However, some microcracks and a small amount of porosity are observed in it. The arrows represent interparticle defects and oxide layers between the splats in Fig. 4d. The lack of unmelt round particles and severe deformation of splats confirm that the particles have been heated above the melting temperature during HVOF. There is no sign of oxide phase in CGS coating while a continuous network of oxide phase is visible in HVOF coating [51]. In CGS, high-velocity particles impacted to the substrate or already deposited particles, are deformed plastically, and can induce compressive stress in the coating. Singh et al. [30] reported that compressive residual stress in cold spraying coating is affected by process parameter. So, a dense layer without any oxidation is attainable by CGS process parameter optimization [30, 59]. In addition, Houdková et al. [27] reported the compressive residual stress in the HVOF sprayed stellite alloys. In the HVOF coating, the compressive residual stress is developed due to the significant peening effect of the high velocity molten or partially molten particles [8, 59].

\subsection{XRD characterization}

The XRD results of the initial powder and the resultant coatings are shown in Figure 4. The initial powder consists of Co-Cr-Mo fcc solid solution and very low-intensity peak distinguishable as Fe-Cr bcc phase, which was developed due 
to the extreme cooling rate of the powder processing method $[6,28,60]$. Five strong peaks of the fcc phase in the feedstock are associated to the (1 111$),(20$ 0), (2 2 0), (311) and (222) atomic planes. High cooling rate of gas atomization process and a small amount of $\mathrm{C}$ in the powder composition lead to the formation of ultrafine Fe-Cr solid solution microstructures as an outer shell in some particles [60], and hindering of carbide precipitates [28], which is not detectable in the XRD spectra and the SEM micrograph. All diffraction peaks in CGS sample are, however, significantly broadened comparing to those of the feedstock powder and HVOF samples [61, 62]. This broadening in CGS could be attributed to grain refinement and/or induced micro-stresses caused by the deposition process [63]. Also due to very low intensity of Fe-Cr, this phase is not visible, which is related to the broadening of $\mathrm{Co}$ fcc phase peak. In the cold spray process, hightemperature phase transformations are avoided due to short time exposure of the feedstock to hot gas stream and also the drop in gas temperature in the nozzle throat section [37]. There is no evidence of oxide or undesirable phases in CGS, while the particle oxidation during HVOF process leads to Co-Cr-O peak. Two main phases existing in HVOF coating consist of (i) Co-Cr-Mo fcc solid solution and (ii) interlamellar Co-Cr-O phase, coming from melted powder oxidation during the deposition process [28]. Interlamellar oxidation occurs immediately by the lamella reaction with the atmosphere before the next layer deposition [ 28 , $55]$. 


\subsection{Microhardness}

The microhardness profiles of the coatings are shown in Fig. 6. The microhardness of CGS coating is higher than the HVOF coating. There are similarities in the microstructural evolutions of the material in mechanical milling and CGS [31]. It has been shown that severe plastic deformation of cold sprayed stellite particles leads to a large number of twins in the coating [38], which, in turn, increases the microhardness of the coating comparing to that of the feedstock. A higher value of defects in HVOF sprayed layer, and powder melting during the process decreases the microhardness of the coatings.

\subsection{Nano-indentation}

Due to utilizing higher amounts of load in microhardness test, the calculated value is affected by the coatings' characteristics. The higher load of microhardness leads to higher indentation mark, representing the average response of the material. Lower load utilized in nanoindentation test leads to a smaller indentation mark. So the results are less influenced by the interlamellar sliding, porosity and oxide layer and higher value of hardness [64]. Also, in order to avoid the effect of resin on the results of the test, the indentation is performed in the middle of the single particle. There are large scatters in the results of nanoindentation, which are typical in thermal spray coating due to the anisotropic coating properties [55]. Since understanding the significance of thermal spray results is difficult, the student t-test is carried out for interpreting the results. The 
loading-unloading curves of the probed materials are presented in Fig. 7. In the case of feedstock, greater plasticity is observed during indentation test, which means that higher energy is stored in the material after the indentation due to its lower hardness value [65]. The average values of Young's modulus and the hardness values of the coatings are presented in Table 3. It was shown that there is a correlation between grain size and hardness in CGS coatings $[37,66]$. The elastic moduli of thermal spray deposits are in the range of $12 \%-78 \%$ of dense bulk materials, depending on the materials, spray processes, and post-treatments [67]. During CGS, the large plastic deformation at lower temperature than HVOF results in higher values of hardness and elastic modulus [65]. In HVOF, the melted particles are more deformed and then solidified, so lower hardness of the coating is predictable.

\subsection{Adhesion strength}

The average bond strength of CGS and HVOF samples was obtained as $64 \pm 2$ and $50.4 \pm 5 \mathrm{MPa}$, respectively. Failure occurred at the interface of the coatings and substrates. The fracture surface of the samples is shown in Fig. 8. Besides the similar fracture mode, the better bonding of CGS sample causes more bonded particles to the substrate. The bonded particles are obvious in Figs. 8a and c. Interparticle fracture traces can be observed on the surface. Some voids are visible on the surface of CGS sample as denoted by the circle in Fig. 8a. The presence of these voids and craters suggest that both metallurgical bonding and mechanical 
interlocking between the particles and substrate have been occurred. The white arrows in the inset image of Fig. 8a represent the voids comes from the limited metallurgical bonding site. Metallurgical bonding leads to the higher value of bonding strength in CGS sample rather than in HVOF coating. In spite of the compacted microstructure of CGS sample, the poorly bonded particles acted as stress concentration regions in the coating. When the tensile load is applied, these regions provide a fast crack propagation path-way in the coating, and the tensile strength of the deposite decreases.

\subsection{Wear behavior}

Variation of frictional force was recorded continuously throughout the Ball on Disk (BoD) wear test. By dividing the frictional force by normal load, the coefficient of friction $(\mathrm{CoF})$ was computed and plotted against the distance as represented in Fig. 9. In HVOF coating, the drastic rise of CoF in the first 100m is observable. Whereas the CoF in CGS sample increases continuously during the test. The CoF is stabilized and reached a stable state for both samples after $200 \mathrm{~m}$. The confocal images of the worn surface are represented in Figs. 10a and b. In the sliding wear tests against the WC-Co ball, the CGS sample showed better wear resistance than the HVOF coating. The calculated volume losses of the CGS and HVOF coatings were 0.02218 and $0.03965 \mathrm{~mm}^{3}$, respectively. For a better understanding, the surface morphology of the wear track was investigated by SEM. According to the SEM micrographs (Figs. 10c and d), the wear mechanisms 
of HVOF and CGS samples are different. The differences in the coatings microstructure of both methods can have a significant influence on their tribomechanical properties. The main wear mechanism of HVOF coating are considered to be the adhesive wear comes from the formation of microweld between the mating surface $[46,48]$ and brittle delamination resulting from the three-dimensional oxide net on the inter-splat boundaries $[8,28,46]$. The surface morphology of worn surface of CGS sample is represented in Fig. 10c. No sign of abrasive wear and/or cracks and brittle cracking is seen even at the high magnifications in CGS coating (Fig. 10c). The two-phases are distinguishable on the worn surface of the CGS sample. The white gray part represents stellite, and the dark gray one shows Fe-Cr solid solution as represented in EDS spectrum (Fig. 10e). On the other hand, longitudinal and traverse cracks are visible at the dark zone of HVOF sample (indicated by white arrows in Fig. 10d). The white regions are Co solid solution phase in Fig. 10d. The EDS spectra of both phases are shown in Fig. 10f. The wear mechanism in these two regions are different. The dark zone comes from the detachment of splats along the oxide layers. The wavy nature of this area is related to the high tangential force applied to the surface during the BoD test. The oxide layers absorb more humidity from the atmosphere; this increases the interaction between the oxide layer and the counterpart [28]. These events result in the formation of longitudinal cracks. Also there are some visible cracks inside the white regions, attributable to the crack propagation path. The presence of oxide layer in the HVOF sprayed coating leads 
to a dynamic condition involving the continuous formation and breaking of tribolayer during the sliding. Since the tribo-layer formation needs a high stress level; this phenomenon increases the value of $\mathrm{CoF}$ for $\mathrm{HVOF}$ coating rather than for CGS coating.

SEM micrographs of the edge of wear track and wear debris are shown in Fig. 11. In CGS sample, the wear debris comes from tribo-layer delamination due to crack initiation and propagation in the wear track edge (Fig. 11a). Small portion of HVOF coating delaminated locally by the interlamellar brittle detachment, which leaves small pits on the surface of the coating [51]. The pits morphology suggests that delamination usually involves cracking and pullout of splats. The propagation of cracks starts from the coating's defects such as porosity and oxide inclusions. The lamellar boundaries between the splats are the weakest region of the coatings and crack initiation and propagation are most likely to occur in it [28, 51]. The higher $\mathrm{CoF}$ of the HVOF coating corresponds to the splat delamination during the wear test [8]. In HVOF sample, large particles in the wear debris are visible due to the splats delamination as indicated in Fig. 11b. The EDS results showed the amount of oxide content in the wear debris of CGS coating and HVOF sample as 8.4 and $19.4 \mathrm{wt} . \%$, respectively. These values are higher than the initial value of oxygen in the coatings, so the oxidation of debris occurs during the wear test. 
Due to the alloying elements in the Co-based alloy, stellites retain their fcc phase even at room temperature. However, sufficiently high stress causes the transformation of fcc phase to hcp phase which ends with the formation of a surface tribo-layer consisting of aligned hcp crystals in $\gamma$ phase matrix. The formation of aligned hcp layer at the surface is essential for the tribological behavior of stellite alloys [4]. The hcp crystals promote work hardening of tribolayer [4]. The hcp crystals promote work hardening of tribo-layer [68] and have a lower friction coefficient and higher wear resistance $[8,33,38]$. In this regard, by accumulation of enough damage, the tribo-layer delaminates and the wear proceeds $[1,69]$. Therefore, the tribo-layers' resistance to delamination is essential factor for the superior resistance of stellite alloys to galling wear $[1,50$, $68]$.

The XRD patterns of wear tracks of the samples are represented in Fig. 12. The XRD peaks revealed the presence of the HCP phase in both samples. The martensitic transformation was reported by some authors for CGS stellite alloy coatings $[4,38,70]$. As shown, there are two main differences between the XRD peaks before and after the wear test. Varano et al. [71] reported that the local phenomenon of nucleation and growth of the hcp phase around the stacking faults causes the fcc phase peak to broaden. This tiny hcp phase is dispersed throughout the fcc matrix. The hcp peak intensity for CGS sample is higher than that for 
HVOF sample. As mentioned in the previous section, the tribo layer delamination in HVOF deposit proceeds the coatings' wear.

During the strain induced transformation, tiny hcp phase distributes in the fcc matrix, which leads to higher hardness comparing to the initial fcc phase. According to the XRD spectra phase transformation has occurred in both samples. Although the ratio of hcp to fcc phase peak intensity in CGS sample is higher than in HVOF sample, the presence of a higher value of hop phase in CGS sample decreases the value of $\mathrm{CoF}$ [8]. The scanning electron micrographs of WC counterparts are shown in Fig. 13. Overall, there is no sign of wear of the WCCo ball in both samples. In CGS, the uniform tribo-layer with small cracks are visible on the surface of WC ball (Figs. 13a and c). It seems that, by propagation of the cracks in the bonded layer of Stellite 21, a small portion of tribo-layer is removed. The tension stress in this layer, developed during the wear test, is the main reason for crack initiation and propagation. However, in HVOF sample, the counterpart has an irregular surface morphology. As shown in Figs. 13b and d, the surface of the ball is not uniform, and detached areas are visible in this image. The EDS result from the bonded zone is represented in Fig. 13f. Unlike the EDS spectrum of a bonded area of CGS counterpart (Fig. 13e), the oxide content for the counterpart of HVOF sample is much higher. The existance of a continuous network of oxide phase is the main weak point of HVOF coating as it causes quick crack propagation in this area [40]. By crack propagation, the wear debris 
separates quickly, and a new layer form as a tribo-layer on the surface of the ball. These phenomena cause hcp layer removal and formation of a new hcp layer needs higher force, and consequently higher value of coefficient of friction comparing to CGS sample [8]. Additionally, the lower and more stable CoF of cold sprayed coating can come from the more uniform tribo-layer and less delamination [40]. This result confirms the excellent performance of cold sprayed Stellite 21 sample rather than HVOF sprayed sample.

\subsection{Oxidation behavior}

The SEM images of the surface of isothermal oxidation samples are shown in Fig. 14. The oxidation resistance of cold sprayed sample can be explained by the characterization of oxide morphology. The morphology of the oxide layer of CGS sample is prismatic. A compact oxide layer with a small amount of porosity has formed on the surface of this sample, while the oxide layer of the oxidized HVOF sample has irregular morphology with higher value of porosity. In HVOF coatings, the higher the value of porosity and the existence of a continuous network of oxide phase between the layers of the coating provide direct contact of oxygen gas with the alloy, so a higher value of oxidation occurrs. Chromium oxide has an irregular and porous morphology [41] while the spinel phase protects the surface by decreasing the formation of none protective oxide. The oxidation process was hindered by development of the spinel phase which decreases the oxygen partial pressure [72]. The compact structure and a small amount of 
porosity in CGS sample reduce the oxygen movement towards the subsurface layers. Furthermore, higher oxidation resistance is expected for CGS sample due to the lower oxygen diffusion through the compact structure of the spinel $\mathrm{CoCr}_{2} \mathrm{O}_{4}$ oxide layer. This phenomenon reduces the partial oxygen pressure at the surface of the sample. In HVOF coating, the oxide scale layer has poor adhesion to the surface, which leads to localized exfoliation [73]. Additionally, Kofstad and Hed [74] indicated that scales on the oxidized sample are spalled off during cooling to room temperature. This phenomenon causes scale removing from the surface of HVOF sample. There are some bonded thick pieces of oxide layer on the surface of HVOF sample, which are shown by white rectangles in Fig. 14b.

The XRD spectra of the oxide layers are represented in Fig. 15. In CGS, the oxidized layer is dominantly composed of chromite or chromium oxide $\left(\mathrm{Cr}_{2} \mathrm{O}_{3}\right)$ and cobalt chromite $\mathrm{CoCr}_{2} \mathrm{O}_{4}$ with spinel structure. The intensity of $\mathrm{CoCr}_{2} \mathrm{O}_{4}$ to $\mathrm{Cr}_{2} \mathrm{O}_{3}$ ratio in CGS is higher than in the HVOF sprayed sample. It has been shown that a higher amount of $\mathrm{CoCr}_{2} \mathrm{O}_{4}$ spinel phase leads to the higher protective effect of the oxide layer comparing to the $\mathrm{Cr}_{2} \mathrm{O}_{3}$ phase [41]. Oxide phase spallation (Fig. 14f) causes a thinner oxide layer on the surface of HVOF coating. It seems that the presence of substrate peak on the XRD spectrum of this sample is related to the lower thickness of the oxide layer in comparison with the CGS sample. According to the finding of Phalnikar et al. [75] in Co-base alloy with a Cr content less than $30 \%$, a conglomerate of the oxides of cobalt and chromium forms at 
$900^{\circ} \mathrm{C}$. Therefore, a higher value of $\mathrm{CoCr}_{2} \mathrm{O}_{4}$ exists in the surface layer comparing to the $\mathrm{Cr}_{2} \mathrm{O}_{3}$ phase. Also, the hexagonal phase starts to appear and coexists with cubic phase in both samples (Fig. 15). The peak intensity for CGS sample is higher than HVOF sample. In pure cobalt and cobalt based alloys, the metastable fcc phase is usually present at room temperature due to the slow nature of fcc to hcp transformation, and hep formation is triggered only by mechanical stress or time at elevated temperature. The alloying elements such as $\mathrm{Cr}$, Mo increase transformation temperature $[1,40,76]$. In the HVOF sample, due to the oxidation during the deposition and chromium oxide formation, the $\mathrm{Cr}$ concentration decreases in the alloy composition leading to a decrease in the transformation temperature. So, long exposure of the coating to high temperature during the oxidation test leads to moderate peaks of hcp phase which means the transformation of unstable fcc phase occurs in this sample. In CGS sample, due to the lower temperature of the process, no oxidation occurs. The higher value of $\mathrm{Cr}$ in the coating leads to the higher temperature of the hcp phase transformation to fcc [76]. So, higher peak intensity is observed in XRD spectrum after the oxidation test.

As specified by Li et al.[77], during the oxidation of cobalt base alloy, a duplex layer film forms on the surface consisting of an outer CoO-rich layer and an inner layer of $\mathrm{Cr}_{2} \mathrm{O}_{3}$-rich. During the oxidation, the Co-rich layer is replaced gradually with chromium oxide. In HVOF sprayed sample, due to the lower adhesion of the 
oxide layer to the substrate, the oxide layer is detached and a new Co-rich layer is formed again. This phenomenon leads to the sharp peak of $\mathrm{CoO}$ in the XRD spectrum (Fig. 15). On the other side, in CGS, good adhesion of this layer prevents the formation of new $\mathrm{CoO}$ layer.

\section{CONCLUSION}

In this study, the microstructure-property relationships and tribomechanical and oxidation evaluations of Stellite 21 coatings deposited by CGS and HVOF was evaluated. It is demonstrated that dense Stellite 21 coating was successfully coldsprayed using $\mathrm{N}_{2}$ carrier gas while preventing phase transformation, decomposition and oxidation of the feedstock powders, rather HVOF process. The higher adhesive strength and oxidation resistance are unique technical advantages of CGS coating over HVOF. The XRD peak broadening in CGS sample arises from severe plastic deformation of the particles during the process.

The wear process in the CGS sample consisted of two main mechanisms (i) martensitic phase transformation on the surface layer, and (ii) delamination of the transformed layer during the wear test. Martensitic phase transformation occurred due to the contact load and sliding movement of the sample during the wear test. The coating integrity in CGS sample prevented layer delamination during the sliding wear test, which decreased the wear rate of the sample comparing to HVOF sample. In HVOF sprayed sample, wear proceeds mainly due to the splat delamination, which occurrs due to the high value of oxide phase between the 
splats. The presence of continuous oxide layer in the HVOF sprayed coating led to a dynamic condition involving formation and breaking of tribo-layer during the sliding test. The tribo-layer is removed from the surface of the sample, and the counterpart hinders the stabilization of the process and increases the samples' coefficient of friction. Furthermore, by prohibiting the delamination, the wear rate is reduced. So, due to the good bonding between splats and absence of oxide layer in CGS, the tribo-layer removal is hindered and the wear rate is decreased.

The oxidation test results showed that the compact structure of CGS sample decreases the coating oxidation and leads to a dense spinel oxide phase at the surface of the sample. In HVOF, the oxide layer is porous and detaches in some regions and a new Co-rich layer formed again, which leads to the sharp peak of $\mathrm{CoO}$ in XRD spectrum. On the other side, in CGS, good adhesion of this layer prevents the formation of new $\mathrm{CoO}$ layer, and $\mathrm{CoCr}_{2} \mathrm{O}_{4}$ spinel phase is the dominant phase in the CGS sample.

\section{References}

[1]Davis J.R., Nickel, cobalt, and their alloys, ASM international, 2000.

[2]Zhu Z., Ouyang C., Qiao Y., Zhou X., Wear Characteristic of Stellite 6 Alloy Hardfacing Layer by Plasma Arc Surfacing Processes, Scanning, 2017, vol. 2017, pp.

https://doi.org/10.1155/2017/6097486.

[3]Motallebzadeh A., Atar E., Cimenoglu H., Raman spectroscopy characterization of hypo-eutectic CoCrWC alloy tribolayers, Industrial Lubrication and Tribology, 2016, vol. 68, pp 515-20.

https://doi.org/10.1108/ILT-11-2015-0168.

[4]Persson D.H.E., On the Mechanisms behind the Tribological Performance of Stellites, Uppsala, Acta Universitatis Upsaliensis, 2005.

[5]Radu I., Li D.Y., Llewellyn R., Tribological behavior of Stellite 21 modified with yttrium, Wear, 2004, vol. 257, pp 1154-66. https://doi.org/10.1016/j.wear.2004.07.013.

[6]Yu H., Ahmed R., de Villiers Lovelock H., A Comparison of the Tribo-Mechanical Properties of a Wear Resistant Cobalt-Based Alloy Produced by Different Manufacturing Processes, Journal of Tribology, 2007, vol. 129, pp 586-94. https://doi.org/10.1115/1.2736450. 
[7]Li B., Jin Y., Yao J., Li Z., Zhang Q., Solid-state fabrication of WCp-reinforced Stellite-6 composite coatings with supersonic laser deposition, Surface and Coatings Technology, 2017, vol. 321, pp 38696. https://doi.org/10.1016/i.surfcoat.2017.04.062.

[8]Houdková Š., Pala Z., Smazalová E., Vostřák M., Česánek Z., Microstructure and sliding wear properties of HVOF sprayed, laser remelted and laser clad Stellite 6 coatings, Surface and Coatings Technology, 2017, vol. 318, pp 129-41. https://doi.org/10.1016/j.surfcoat.2016.09.012.

[9]Frenk A., Kurz W., Microstructural effects on the sliding wear resistance of a cobalt-based alloy, Wear, 1994, vol. 174, pp 81-91. https://doi.org/10.1016/0043-1648(94)90089-2.

[10]Rajeev G.P., Kamaraj M., Bakshi S.R., Hardfacing of AISI H13 tool steel with Stellite 21 alloy using cold metal transfer welding process, Surface and Coatings Technology, 2017, vol. 326, pp 63-71. https://doi.org/10.1016/i.surfcoat.2017.07.050.

[11]Apay S., Gulenc B., Wear properties of AISI 1015 steel coated with Stellite 6 by microlaser welding, Materials \& Design, 2014, vol. 55, pp 1-8. http://dx.doi.org/10.1016/j.matdes.2013.09.056. [12]Singh R., Kumar D., Mishra S.K., Tiwari S.K., Laser cladding of Stellite 6 on stainless steel to enhance solid particle erosion and cavitation resistance, Surface and Coatings Technology, 2014, vol. 251, pp 87-97. http://dx.doi.org/10.1016/i.surfcoat.2014.04.008.

[13]Kusmoko A., Dunne D.P., Li H., A Comparative study for wear resistant of Stellite 6 coatings on nickel alloy substrate produced by laser cladding, HVOF and plasma spraying techniques, 2014, vol. 4, pp 32-6.

[14]Luo F., Lupoi R., Cockburn A., Sparkes M., O'Neill W., Yao J.-h., Characteristics of Stellite 6 Deposited by Supersonic Laser Deposition Under Optimized Parameters, Journal of Iron and Steel Research, International, 2013, vol. 20, pp 52-7. http://dx.doi.org/10.1016/S1006-706X(13)60056-4. [15]Rao K.P., Damodaram R., Rafi H.K., Ram G.D.J., Reddy G.M., Nagalakshmi R., Friction surfaced Stellite6 coatings, Materials Characterization, 2012, vol. 70, pp 111-6.

https://doi.org/10.1016/i.matchar.2012.05.008.

[16]Travis F.W., Johnson W., EXPLOSIVE WELDING OF STELLITE TO STAINLESS STEEL, in: Tobias S.A., Koenigsberger F. (editors), Advances in Machine Tool Design and Research 1967, Pergamon, 1968, pp 1319-32.

[17]Yu H., Ahmed R., Lovelock H.d.V., Davies S., Influence of Manufacturing Process and Alloying Element Content on the Tribomechanical Properties of Cobalt-Based Alloys, Journal of Tribology, 2008, vol. 131, pp 011601--12. https://doi.org/10.1115/1.2991122.

[18]Kaul R., Ganesh P., Tiwari M.K., Singh A.K., Tripathi P., Gupta A., Nath A.K., Laser assisted deposition of graded overlay of Stellite 6 on austenitic stainless steel, Lasers in Engineering, 2002, vol. 12, pp 207-25. https://doi.org/10.1080/0898150021000039301.

[19]Crossland B., Explosive welding of metals and its application, Clarendon Press, 1982.

[20]Findik F., Recent developments in explosive welding, Materials \& Design, 2011, vol. 32, pp 108193. https://doi.org/10.1016/j.matdes.2010.10.017.

[21]Reddy G.M., Prasad K.S., Rao K.S., Mohandas T., Friction surfacing of titanium alloy with aluminium metal matrix composite, Surface Engineering, 2011, vol. 27, pp 92-8.

https://doi.org/10.1179/174329409X451128.

[22]Cinca N., López E., Dosta S., Guilemany J.M., Study of stellite-6 deposition by cold gas spraying, Surface and Coatings Technology, 2013, vol. 232, pp 891-8.

http://dx.doi.org/10.1016/j.surfcoat.2013.06.120.

[23]Richer P., Yandouzi M., Beauvais L., Jodoin B., Oxidation behaviour of CoNiCrAlY bond coats produced by plasma, HVOF and cold gas dynamic spraying, Surface and Coatings Technology, 2010, vol. 204, pp 3962-74. https://doi.org/10.1016/i.surfcoat.2010.03.043.

[24]Bolelli G., Bonferroni B., Laurila J., Lusvarghi L., Milanti A., Niemi K., Vuoristo P., Micromechanical properties and sliding wear behaviour of HVOF-sprayed Fe-based alloy coatings, Wear, 2012, vol. 276-277, pp 29-47. https://doi.org/10.1016/i.wear.2011.12.001. 
[25]Sidhu T.S., Prakash S., Agrawal R.D., Studies of the metallurgical and mechanical properties of high velocity oxy-fuel sprayed stellite-6 coatings on $\mathrm{Ni}$ - and Fe-based superalloys, Surface and Coatings Technology, 2006, vol. 201, pp 273-81. https://doi.org/10.1016/i.surfcoat.2005.11.108. [26]Sidhu B.S., Prakash S., Studies on the behaviour of stellite-6 as plasma sprayed and laser remelted coatings in molten salt environment at $900^{\circ} \mathrm{C}$ under cyclic conditions, Journal of Materials Processing Technology, 2006, vol. 172, pp 52-63. https://doi.org/10.1016/i.jmatprotec.2005.08.018. [27]Houdková Š., Kašparová M., Schubert J., Proc. 21st Intl. Conf. on Metallurgy and Materials, 2012.

[28]Sassatelli P., Bolelli G., Lassinantti Gualtieri M., Heinonen E., Honkanen M., Lusvarghi L., Manfredini T., Rigon R., Vippola M., Properties of HVOF-sprayed Stellite-6 coatings, Surface and Coatings Technology, 2018, vol. 338, pp 45-62. https://doi.org/10.1016/i.surfcoat.2018.01.078. [29]Bolelli G., Bursi M., Lusvarghi L., Manfredini T., Matikainen V., Rigon R., Sassatelli P., Vuoristo P., Tribology of FeVCrC coatings deposited by HVOF and HVAF thermal spray processes, Wear, 2018, vol. 394-395, pp 113-33. https://doi.org/10.1016/i.wear.2017.10.014.

[30]Singh R., Schruefer S., Wilson S., Gibmeier J., Vassen R., Influence of coating thickness on residual stress and adhesion-strength of cold-sprayed Inconel 718 coatings, Surface and Coatings Technology, 2018, vol. 350, pp 64-73. https://doi.org/10.1016/j.surfcoat.2018.06.080.

[31]Ciubotariu C.-R., Frunzăverde D., Mărginean G., Șerban V.-A., Bîrdeanu A.-V., Optimization of the laser remelting process for HVOF-sprayed Stellite 6 wear resistant coatings, Optics \& Laser Technology, 2016, vol. 77, pp 98-103. https://doi.org/10.1016/j.optlastec.2015.09.005.

[32]Cizek J., Matejkova M., Kouril J., Cupera J., Dlouhy I., Potential of New-Generation Electron Beam Technology in Interface Modification of Cold and HVOF Sprayed MCrAlY Bond Coats, Advances in Materials Science and Engineering, 2016, vol. 2016, pp 1-6. https://doi.org/10.1155/2016/9070468.

[33]Karaoglanli A.C., Caliskan H., Gok M.S., Erdogan A., Turk A., A Comparative study of the microabrasion wear behavior of CoNiCrAlY coatings fabricated by APS, HVOF, and CGDS techniques, Tribology Transactions, 2013, vol. 57, pp 11-7. https://doi.org/10.1080/10402004.2013.820372.

[34]Schmidt T., Gärtner F., Assadi H., Kreye H., Development of a generalized parameter window for cold spray deposition, Acta Materialia, 2006, vol. 54, pp 729-42.

https://doi.org/10.1016/j.actamat.2005.10.005.

[35]Nikbakht R., Seyedein S.H., Kheirandish S., Assadi H., Jodoin B., Asymmetrical bonding in cold spraying of dissimilar materials, Applied Surface Science, 2018, vol. 444, pp 621-32.

https://doi.org/10.1016/j.apsusc.2018.03.103.

[36]Moridi A., Hassani-Gangaraj S.M., Guagliano M., Dao M., Cold spray coating: Review of material systems and future perspectives, Surface Engineering, 2014, vol. 30, pp 369-95.

https://doi.org/10.1179/1743294414Y.0000000270.

[37]Assadi H., Kreye H., Gärtner F., Klassen T., Cold spraying - A materials perspective, Acta Materialia, 2016, vol. 116, pp 382-407. https://doi.org/10.1016/j.actamat.2016.06.034.

[38]Cinca N., Guilemany J., Cold Gas Sprayed Stellite-6 Coatings and their Wear Resistance, J Material Sci Eng, 2013, vol. 2, pp 2169-0022.1000. https://doi.org/10.4172/2169-0022.1000122.

[39]Lucchetta G., Giusti R., Vezzù S., Bariani P.F., Investigation and characterization of Stellite-based wear-resistant coatings applied to steel moulds by cold-spray, CIRP Annals, 2015, vol. 64, pp 535-8. https://doi.org/10.1016/j.cirp.2015.04.031.

[40]Houdková Š., Smazalová E., Pala Z., Effect of Heat Treatment on the Microstructure and Properties of HVOF-Sprayed Co-Cr-W Coating, Journal of Thermal Spray Technology, 2016, vol. 25, pp 546-57. https://doi.org/10.1007/s11666-015-0365-5.

[41]Shoja-Razavi R., Laser Surface Treatment of Stellite 6 Coating Deposited by HVOF on 316L Alloy, Journal of Materials Engineering and Performance, 2016, vol. 25, pp 2583-95.

https://doi.org/10.1007/s11665-016-2138-9.

[42]Sidhu H.S., Sidhu B.S., Prakash S., Solid particle erosion of HVOF sprayed NiCr and Stellite-6 coatings, Surface and Coatings Technology, 2007, vol. 202, pp 232-8.

http://dx.doi.org/10.1016/j.surfcoat.2007.05.035. 
[43]Česánek Z., Schubert J., Houdková Š., Bláhová O., Prantnerová M., Deterioration of Local Mechanical Properties of HVOF-Sprayed Stellite 6 after Exposure to High-Temperature Corrosion, Key Engineering Materials, 2015, vol. 662, pp 115-8.

https://doi.org/10.4028/www.scientific.net/KEM.662.115.

[44]Stanford M.K., Jain V.K., Friction and wear characteristics of hard coatings, Wear, 2001, vol. 251, pp 990-6. https://doi.org/10.1016/S0043-1648(01)00719-0.

[45]Bolelli G., Lusvarghi L., Heat treatment effects on the tribological performance of HVOF sprayed Co-Mo-Cr-Si coatings, Journal of Thermal Spray Technology, 2006, vol. 15, pp 802-10.

https://doi.org/10.1361/105996306X146721.

[46]Bolelli G., Cannillo V., Lusvarghi L., Montorsi M., Mantini F.P., Barletta M., Microstructural and tribological comparison of HVOF-sprayed and post-treated M-Mo-Cr-Si (M=Co, Ni) alloy coatings, Wear, 2007, vol. 263, pp 1397-416. https://doi.org/10.1016/j.wear.2006.12.002.

[47]Houdková Š., Smazalová E., The Influence of High Temperature Exposure on the Wear of Selected HVOF Sprayed Coatings, Defect and Diffusion Forum, 2016, vol. 368, pp 55-8.

https://doi.org/10.4028/www.scientific.net/DDF.368.55.

[48]Singh H., Sidhu B.S., Prakash S., Performance of HVOF Sprayed NiCr and Stellite-6 Coatings under Pin on Disc Wear Testing, Materials Science Forum, 2012, vol. 701, pp 21-9.

https://doi.org/10.4028/www.scientific.net/MSF.701.21.

[49]Seraj R.A., Abdollah-zadeh A., Dosta S., Canales H., Assadi H., Cano I.G., The effect of traverse speed on deposition efficiency of cold sprayed Stellite 21, Surface and Coatings Technology, 2019, vol. 366, pp 24-34. https://doi.org/10.1016/j.surfcoat.2019.03.012.

[50]Cinca N., Guilemany J., Cold Gas Sprayed Stellite-6 Coatings and their Wear Resistance, J Material Sci Eng, 2013, vol. 2, pp 1-6. https://doi.org/10.4172/2169-0022.S1.004.

[51]Sassatelli P., Bolelli G., Lusvarghi L., Manfredini T., Rigon R., Manufacturing and Properties of High-Velocity Oxygen Fuel (HVOF)-Sprayed FeVCrC Coatings, Journal of Thermal Spray Technology, 2016, vol. 25, pp 1302-21. https://doi.org/10.1007/s11666-016-0451-3.

[52]Bae G., Kang K., Na H., Kim J.-J., Lee C., Effect of particle size on the microstructure and properties of kinetic sprayed nickel coatings, Surface and Coatings Technology, 2010, vol. 204, pp 3326-35. http://dx.doi.org/10.1016/j.surfcoat.2010.03.046.

[53]Cho T.Y., Yoon J.H., Yoon S.H., Joo Y.K., Choi W.H., Son Y.B., The effects of particle size on the surface properties of an HVOF coating of WC-Co, Journal of Korean Institute of Metals and Materials, 2017, vol. 55, pp 227-31. https://doi.org/10.3365/KJMM.2017.55.4.227.

[54]Feng S.Q., Ma B., Wang X.L., Liu G., Zheng Z.Y., Pan L.P., 2014 International Conference on Advances in Materials Science and Information Technologies in Industry, AMSITI 2014, Xian, 2014, pp 265-8. https://doi.org/10.4028/www.scientific.net/AMM.513-517.265.

[55]Davis J.R., Handbook of thermal spray technology, ASM international, 2004.

[56]Sobolev V.V., Guilemany J.M., Investigation of coating porosity formation during high velocity oxy-fuel (HVOF) spraying, Materials Letters, 1994, vol. 18, pp 304-8. https://doi.org/10.1016/0167577X(94)90012-4.

[57]Mostaghimi J., Chandra S., Droplet Impact and Solidification in Plasma Spraying, Handbook of Thermal Science and Engineering, Cham, Springer International Publishing, 2018, pp 2967-3008.

[58]Dykhuizen R.C., Smith M.F., Gas Dynamic Principles of Cold Spray, Journal of Thermal Spray Technology, 1998, vol. 7, pp 205-12. https://doi.org/10.1361/105996398770350945.

[59]Luo X., Smith G.M., Sampath S., On the Interplay Between Adhesion Strength and Tensile Properties of Thermal Spray Coated Laminates-Part I: High Velocity Thermal Spray Coatings, Journal of Thermal Spray Technology, 2018, vol. 27, pp 296-307. https://doi.org/10.1007/s11666-018-06951.

[60]Duflos F., Stohr J.-F., Comparison of the quench rates attained in gas-atomized powders and melt-spun ribbons of $\mathrm{Co}$ - and Ni-base superalloys: influence on resulting microstructures, Journal of Materials Science, 1982, vol. 17, pp 3641-52. https://doi.org/10.1007/bf00752209. 
[61]Champagne V.K., The cold spray materials deposition process: fundamentals and applications, Elsevier, 2007.

[62]King P.C., Zahiri S.H., Jahedi M., Microstructural refinement within a cold-sprayed copper particle, Metallurgical and Materials Transactions A: Physical Metallurgy and Materials Science, 2009, vol. 40, pp 2115-23. https://doi.org/10.1007/s11661-009-9882-5.

[63]Richer P., Zúñiga A., Yandouzi M., Jodoin B., CoNiCrAlY microstructural changes induced during Cold Gas Dynamic Spraying, Surface and Coatings Technology, 2008, vol. 203, pp 364-71.

https://doi.org/10.1016/i.surfcoat.2008.09.014.

[64]Goldbaum D., Ajaja J., Chromik R.R., Wong W., Yue S., Irissou E., Legoux J.-G., Mechanical behavior of Ti cold spray coatings determined by a multi-scale indentation method, Materials Science and Engineering: A, 2011, vol. 530, pp 253-65. https://doi.org/10.1016/i.msea.2011.09.083.

[65]Yang K., Li W., Niu P., Yang X., Xu Y., Cold sprayed AA2024/Al2O3 metal matrix composites improved by friction stir processing: Microstructure characterization, mechanical performance and strengthening mechanisms, Journal of Alloys and Compounds, 2018, vol. 736, pp 115-23.

https://doi.org/10.1016/j.jallcom.2017.11.132.

[66]Goldbaum D., Chromik R.R., Brodusch N., Gauvin R., Microstructure and Mechanical Properties of Ti Cold-Spray Splats Determined by Electron Channeling Contrast Imaging and Nanoindentation Mapping, Microscopy and Microanalysis, 2015, vol. 21, pp 570-81.

https://doi.org/10.1017/S1431927615000240.

[67]Leigh S.H., Lin C.K., Berndt C.C., Elastic response of thermal spray deposits under indentation tests, Journal of the American Ceramic Society, 1997, vol. 80, pp 2093-9.

https://doi.org/10.1111/i.1151-2916.1997.tb03093.x.

[68]Sidhu T.S., Prakash S., Agrawal R.D., A comparative study of hot corrosion resistance of HVOF sprayed NiCrBSi and Stellite- 6 coated Ni-based superalloy at $900^{\circ} \mathrm{C}$, Materials Science and Engineering: A, 2007, vol. 445-446, pp 210-8. http://dx.doi.org/10.1016/i.msea.2006.09.015. [69]Kusmoko A., Dunne D., Li H., Nolan D., Effect of Two Different Energy Inputs for Laser Cladding of Stellite 6 on P91 and P22 Steel Substrates, Procedia Materials Science, 2014, vol. 6, pp 26-36. http://dx.doi.org/10.1016/j.mspro.2014.07.005.

[70]Cinca N., Guilemany J.M., Structural and properties characterization of stellite coatings obtained by cold gas spraying, Surface and Coatings Technology, 2013, vol. 220, pp 90-7.

https://doi.org/10.1016/j.surfcoat.2012.11.026.

[71]R. Varano, J. D. Bobyn, J. B. Medley, S. Yue, Effect of microstructure on the dry sliding friction behavior of CoCrMo alloys used in metal-on-metal hip implants, Journal of Biomedical Materials Research Part B: Applied Biomaterials, 2006, vol. 76B, pp 281-6.

https://doi.org/10.1002/jbm.b.30370.

[72]Singh H., Puri D., Prakash S., Rama Rao V.V., On the high-temperature oxidation protection behavior of plasma-sprayed Stellite- 6 coatings, Metallurgical and Materials Transactions A, 2006, vol. 37, pp 3047-56. https://doi.org/10.1007/s11661-006-0186-8.

[73]Pala Z., Bai M., Lukac F., Hussain T., Laser Clad and HVOF-Sprayed Stellite 6 Coating in ChlorineRich Environment with $\mathrm{KCl}$ at $700{ }^{\circ} \mathrm{C}$, Oxidation of Metals, 2017, vol. 88, pp 749-71.

https://doi.org/10.1007/s11085-017-9776-7.

[74]Kofstad P., Hed A., Oxidation of Co-25 w/o Cr at High Temperatures, Journal of the Electrochemical Society, 1969, vol. 116, pp 1542-50. https://doi.org/10.1149/1.2411603.

[75]Phalnikar C., Evans E., Baldwin W., High Temperature Scaling of Cobalt-Chromium Alloys, Journal of the Electrochemical Society, 1956, vol. 103, pp 429-38. https://doi.org/10.1149/1.2430374.

[76]Favre J., Recrystallization of L-605 cobalt superalloy during hot-working process, Tohoku University, 2012.

[77] Li Y., Tang N., Tunthawiroon P., Koizumi Y., Chiba A., Characterisation of oxide films formed on Co-29Cr-6Mo alloy used in die-casting moulds for aluminium, Corrosion Science, 2013, vol. 73, pp 72-9. https://doi.org/10.1016/j.corsci.2013.03.026. 


\section{Tables}

Table 1. Spray parameters for HVOF spraying of Stellite-21

\begin{tabular}{|c|c|c|c|c|c|c|}
\hline \multirow{2}{*}{$\begin{array}{c}\text { Spray } \\
\text { distance } \\
(\mathbf{m m})\end{array}$} & \multicolumn{3}{|c|}{ Gas flow rate (1/min) } & \multirow{2}{*}{$\begin{array}{l}\text { Number of } \\
\text { layers }\end{array}$} & \multirow{2}{*}{$\begin{array}{c}\text { Nozzle } \\
\text { Traverse } \\
\text { speed }(\mathbf{m m} / \mathbf{s})\end{array}$} & \multirow{2}{*}{$\begin{array}{c}\text { Step Size } \\
(\mathbf{m m})\end{array}$} \\
\hline & Hydrogen & Oxygen & Air & & & \\
\hline 250 & 738 & 214 & 344 & 10 & 100 & 5 \\
\hline
\end{tabular}


Table 2. Properties of Stellite 21 coatings produced by HVOF and CGS

\begin{tabular}{ccc}
\hline Coating properties & CGS & HVOF \\
\hline Microstructural features & $\begin{array}{c}\text { Pores and } \\
\text { porosity }\end{array}$ & $\begin{array}{c}\text { Porosity and inter- } \\
\text { lamellar cracks }\end{array}$ \\
Surfaces roughness Ra $(\boldsymbol{\mu m})$ & $18.5 \pm 1.6$ & $4.9 \pm 0.4$ \\
& $\sim 0$ & $6.1 \pm 1.3$ \\
Oxide phase content $(\%)$ & $0.21 \pm 0.15$ & $0.75 \pm 0.15$ \\
Porosity level $(\%)$ &
\end{tabular}


Table 3. The average values of elastic modulus and hardness of the splats in CGS and HVOF samples

\begin{tabular}{ccc}
\hline Sample name & $\begin{array}{c}\text { Elastic modulus } \\
(\mathbf{G P a})\end{array}$ & Hardness (GPa) \\
\hline HVOF & $194 \pm 22.5$ & $7.78 \pm 1.2$ \\
CGS & $251 \pm 27$ & $10.87 \pm 1.1$ \\
\hline
\end{tabular}




\section{List of Figure captions}

Figure 1. (a) The morphology of Stellite 21 powder taken by SEM, (b) the etched cross-section of feedstock provided by optical microscopy, and (c) particle size distribution of the feedstock.

Figure 2. Figure 2. Surface morphology of as-sprayed coatings; (a) CGS and (b) HVOF. Higher magnifications of the coatings; (c) spherical morphology of the bonded particle and metallic jets around it (represented by white arrow), (d) the highly deformed particles in HVOF coating.

Figure 3. OM micrographs of the coatings' cross-section: (a) CGS and (b) HVOF sprayed coatings; (c) and (d) SEM micrographs of the coatings' interface.

Figure 4. OM images of the etched coatings' cross-section of (a) CGS and (b) HVOF sprayed layers. (c) and (d) are SEM micrographs with higher magnification of (a) and (b), respectively.

Figure 5. XRD spectra of feedstock, CGS and HVOF coatings.

Figure 6. Microhardness profiles of the cross-sections of CGS and HVOF deposited coatings.

Figure 7. Load vs. displacement curve for initial powder, CGS and HVOF sprayed sample. The inset image shows the initial part of the nanoindentation test.

Figure 8. SEM micrographs of the fracture surfaces of the adhesion samples: (a) CGS sample, the inset image shows higher magnification of the the fracture surface and the voids are represented by white arrows, (b) HVOF sample. Cobalt mapping of the fracture surfaces of (c) CGS and (d) HVOF adhesive samples.

Figure 9. The friction coefficients of CGS and HVOF sprayed coatings.

Figure 10. The confocal micrographs of the worn surface in (a) CGS and (b) HVOF. Backscattered micrographs of the wear track show the phase distribution on the surface of the coatings in (c) CGS and (d) HVOF. The EDS spectra of (e) spectrum 1 and spectrum 2 and (f) spectrum 3 and spectrum 4 .

Figure 41. SEM micrographs of the edge of the worn surface of (a) CGS and (b) HVOF samples. The white arrows represent the initial groove coming from surface preparation before the test. The morphology of wear debris collected for (c) CGS and (d) HVOF sprayed wear samples.

Figure 52. XRD spectra of the samples before and after the wear test.

Figure 63. SEM micrographs of WC ball counterparts' surface for (a) CGS and (b) HVOF samples. Higher magnification of the surface of the balls: (c) CGS and (d) HVOF samples. The black arrows in (e) and (f) represent the oxygen peak in the EDS spectrum taken from the rectangles represented in (c) and (d), respectively.

Figure 74. SEM micrographs from the surface morphology of the oxide layer formed on the (a) CGS and (b) HVOF samples. Higher magnification of the surface of the samples: (c) CGS and (d) HVOF. The bonded thick pieces of oxide layer on the surface of HVOF sample are shown by white rectangles. The cross-section of (e) CGS oxidized samples showing a good bonded oxide layer and (f) HVOF sample representing the oxide layer spallation. The oxide layers represented by black arrows. 
Figure 85. XRD patterns of the surface of the oxidation samples. 


\section{Figures}
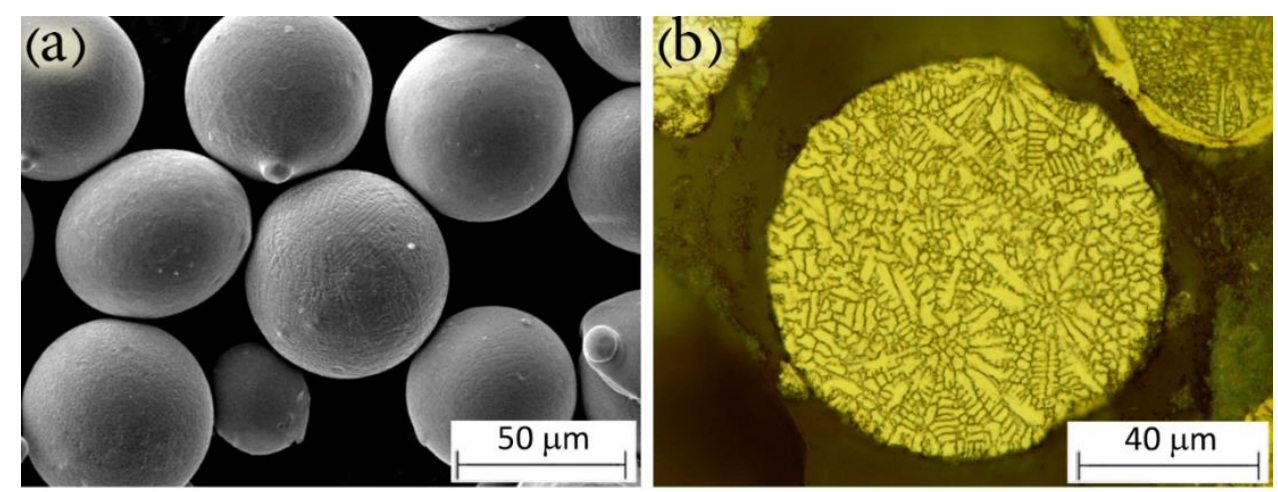

(C)

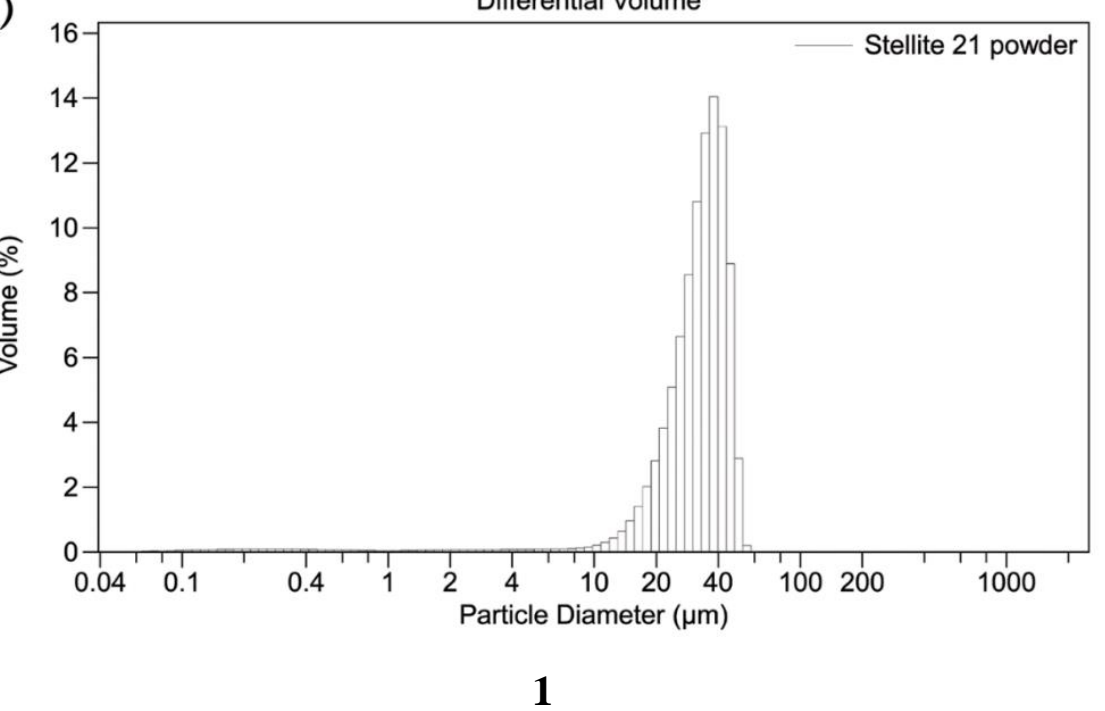

1 

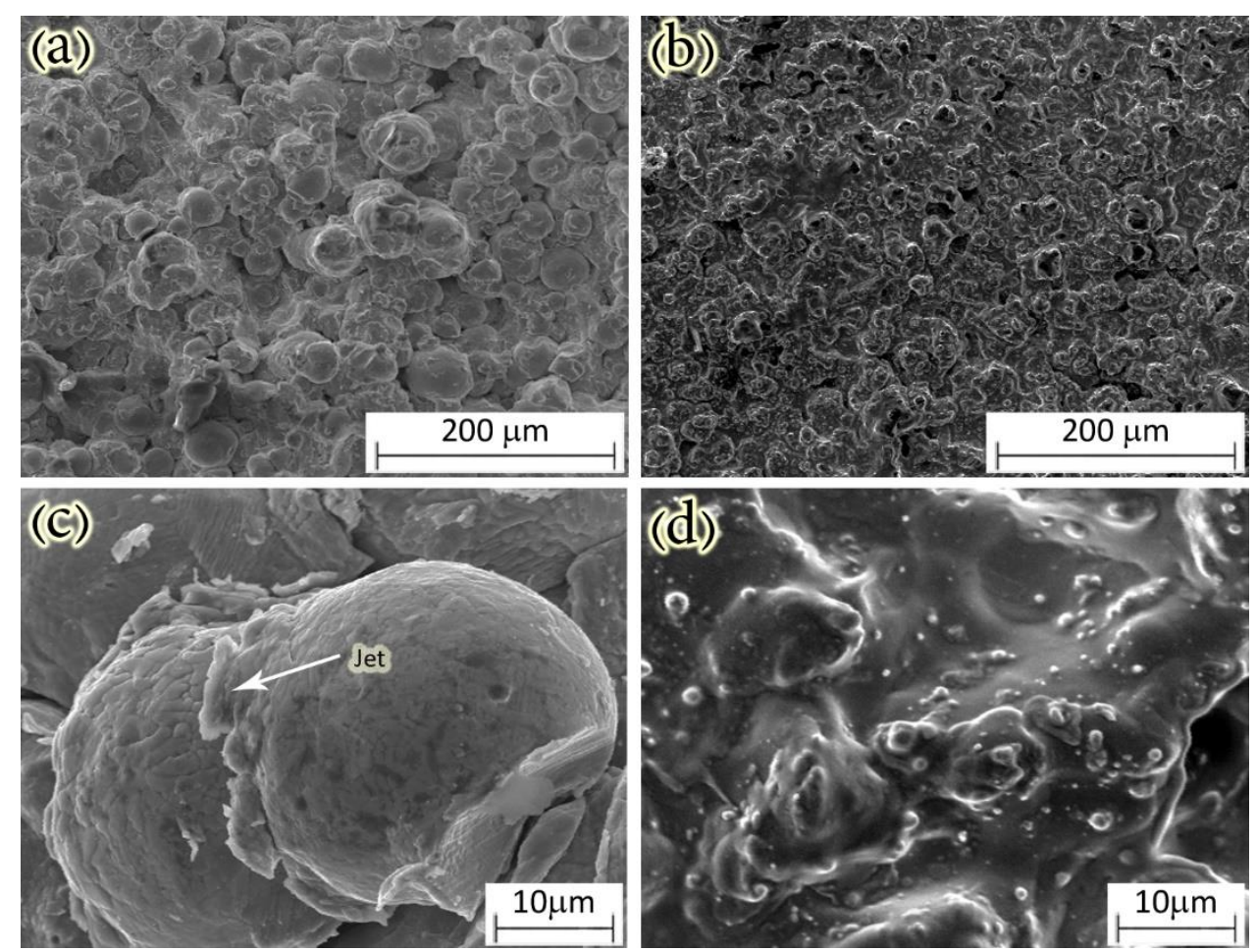

2 

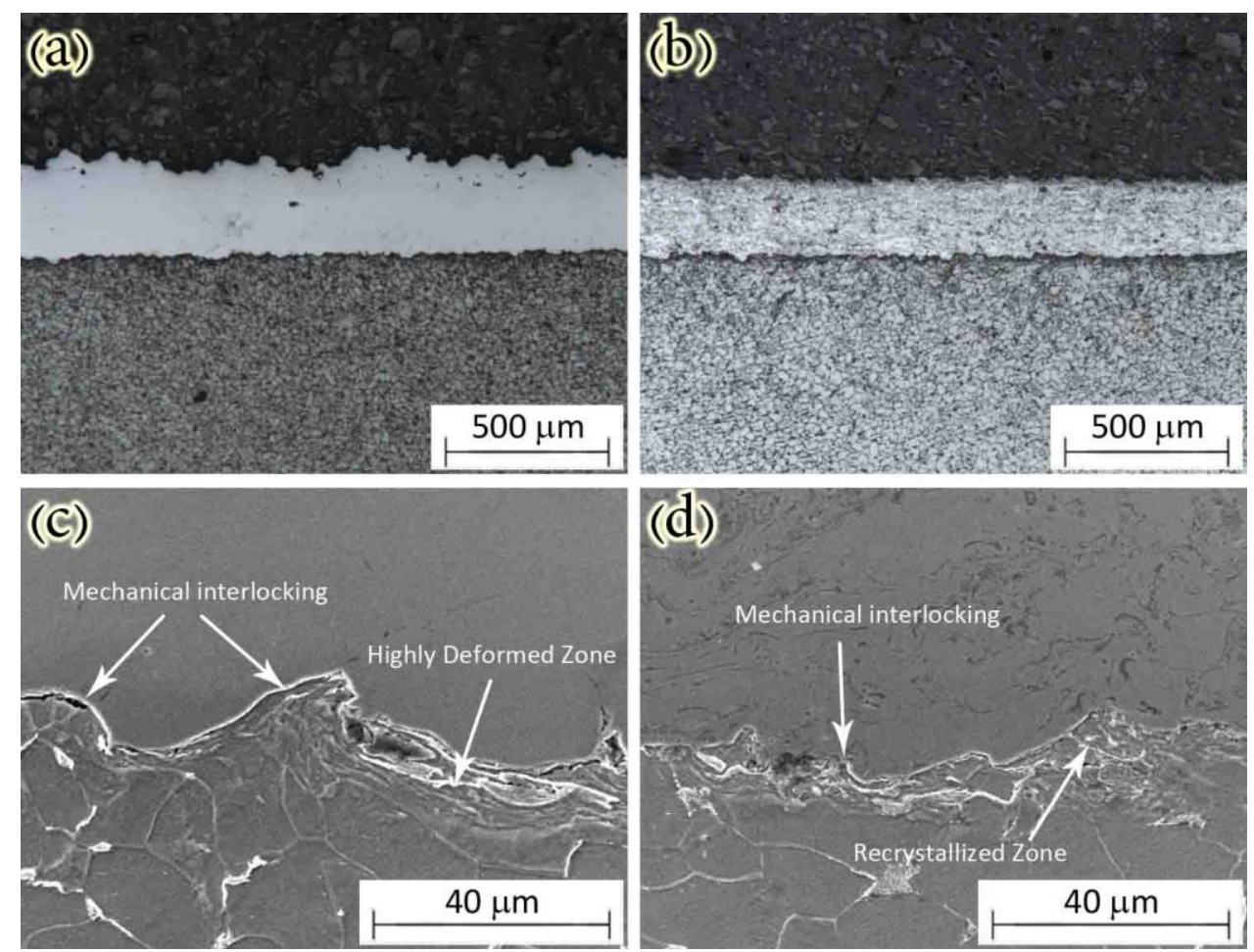

(d)

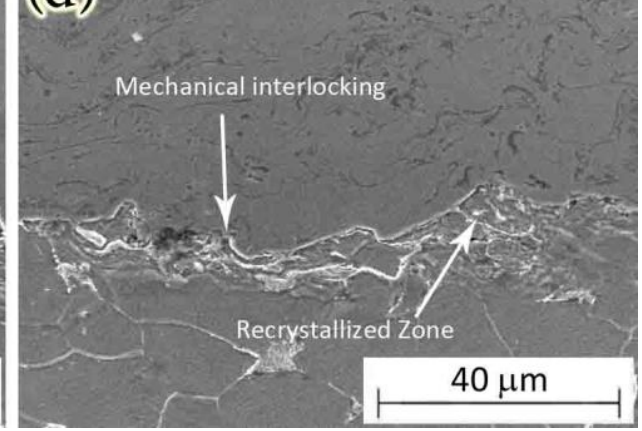



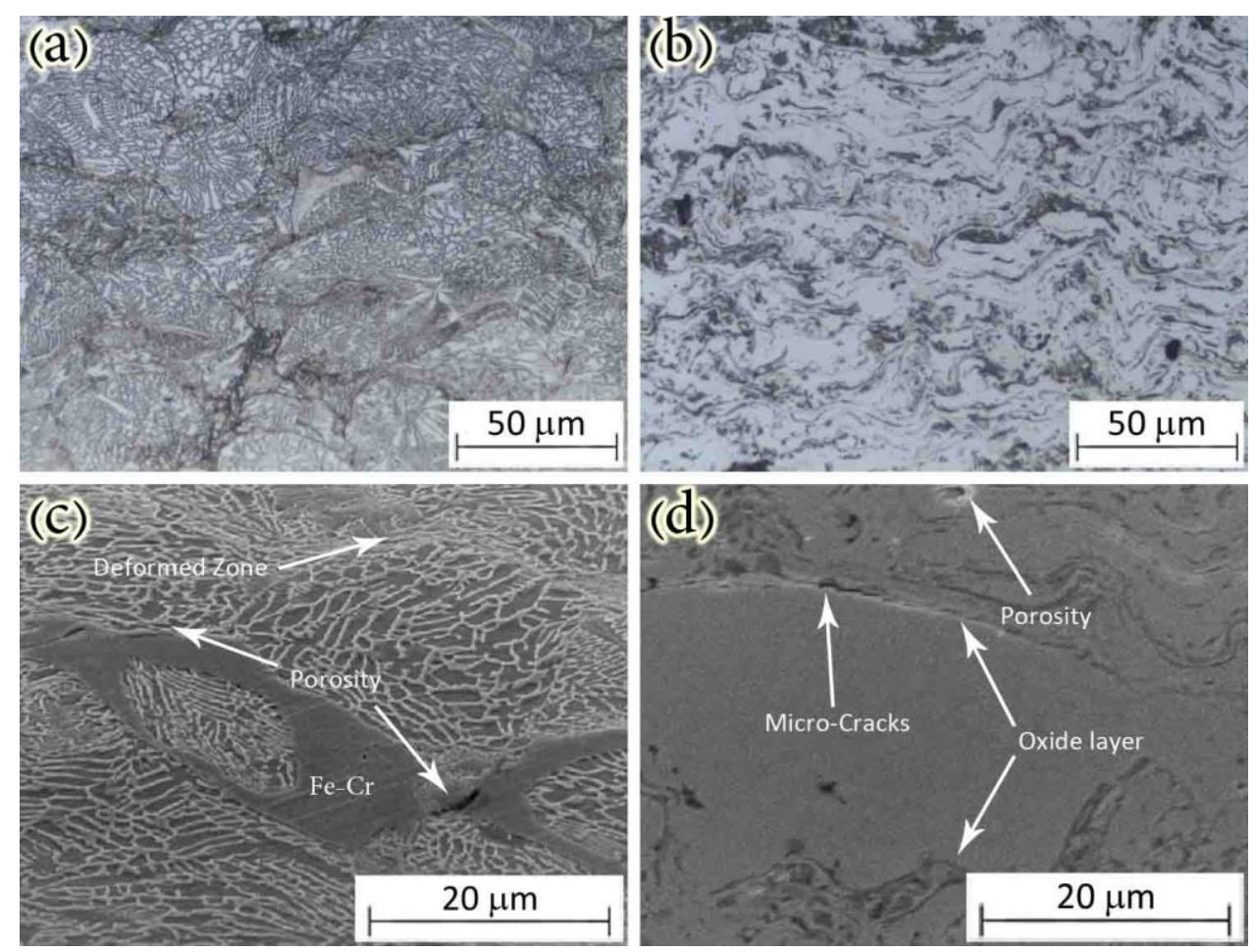

4 


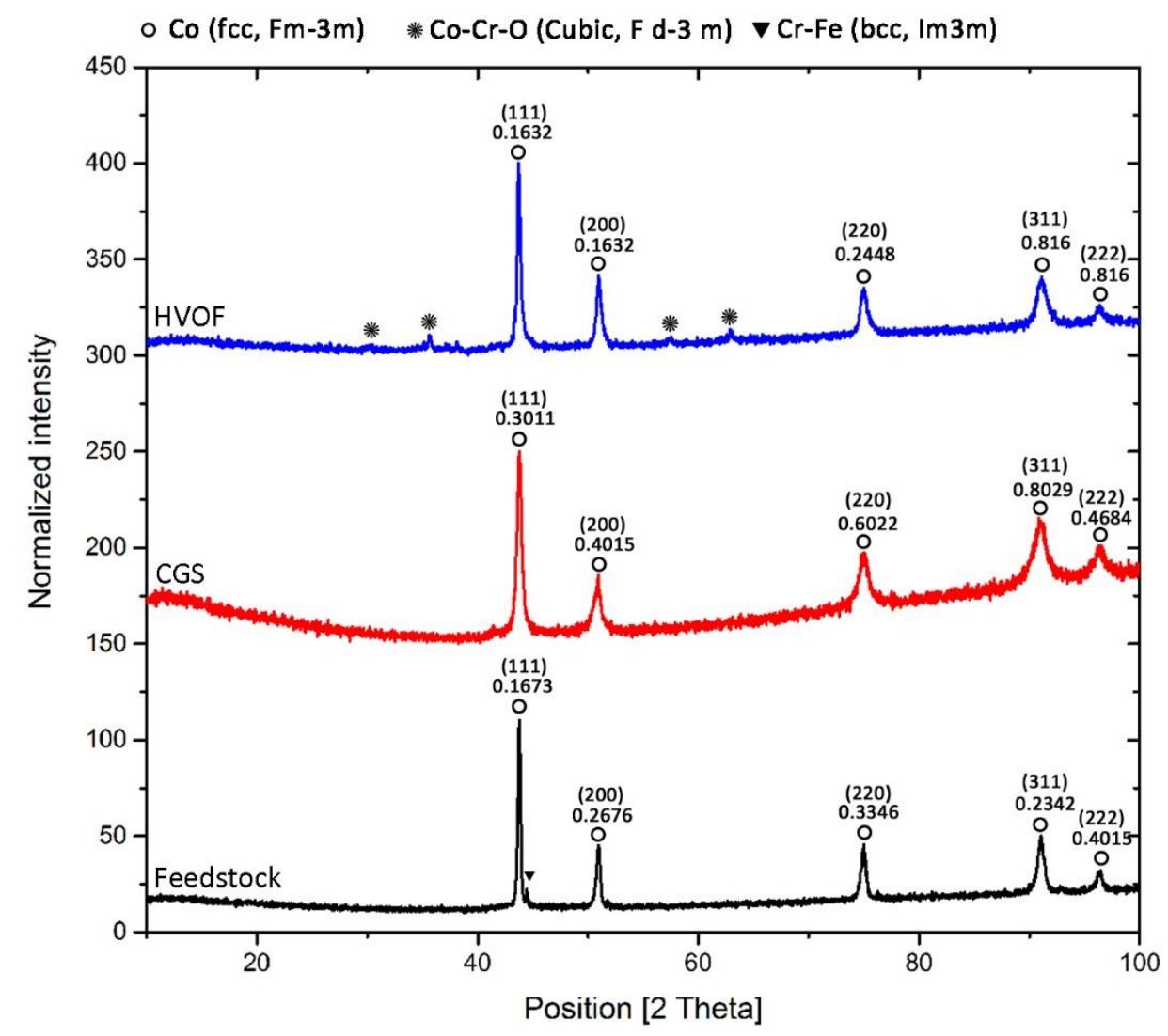

5 


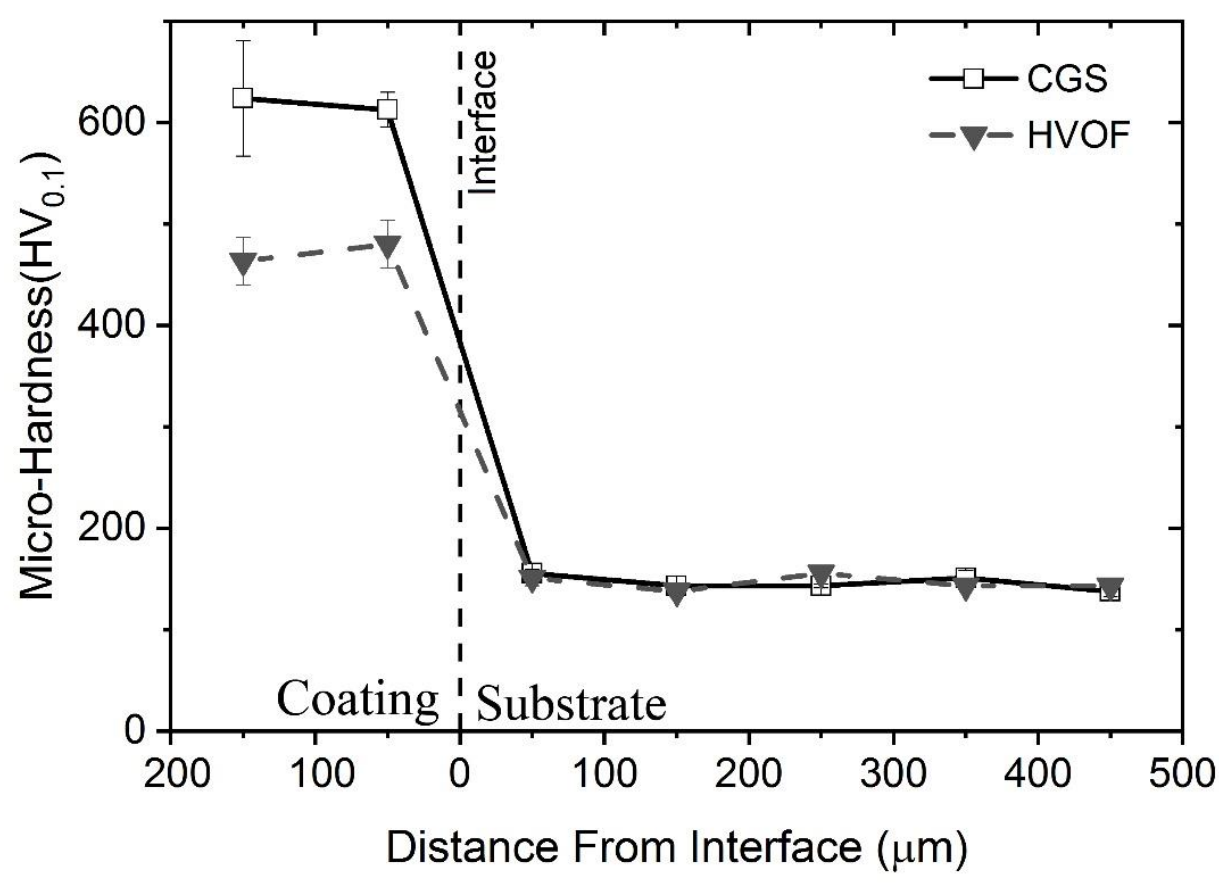

6 


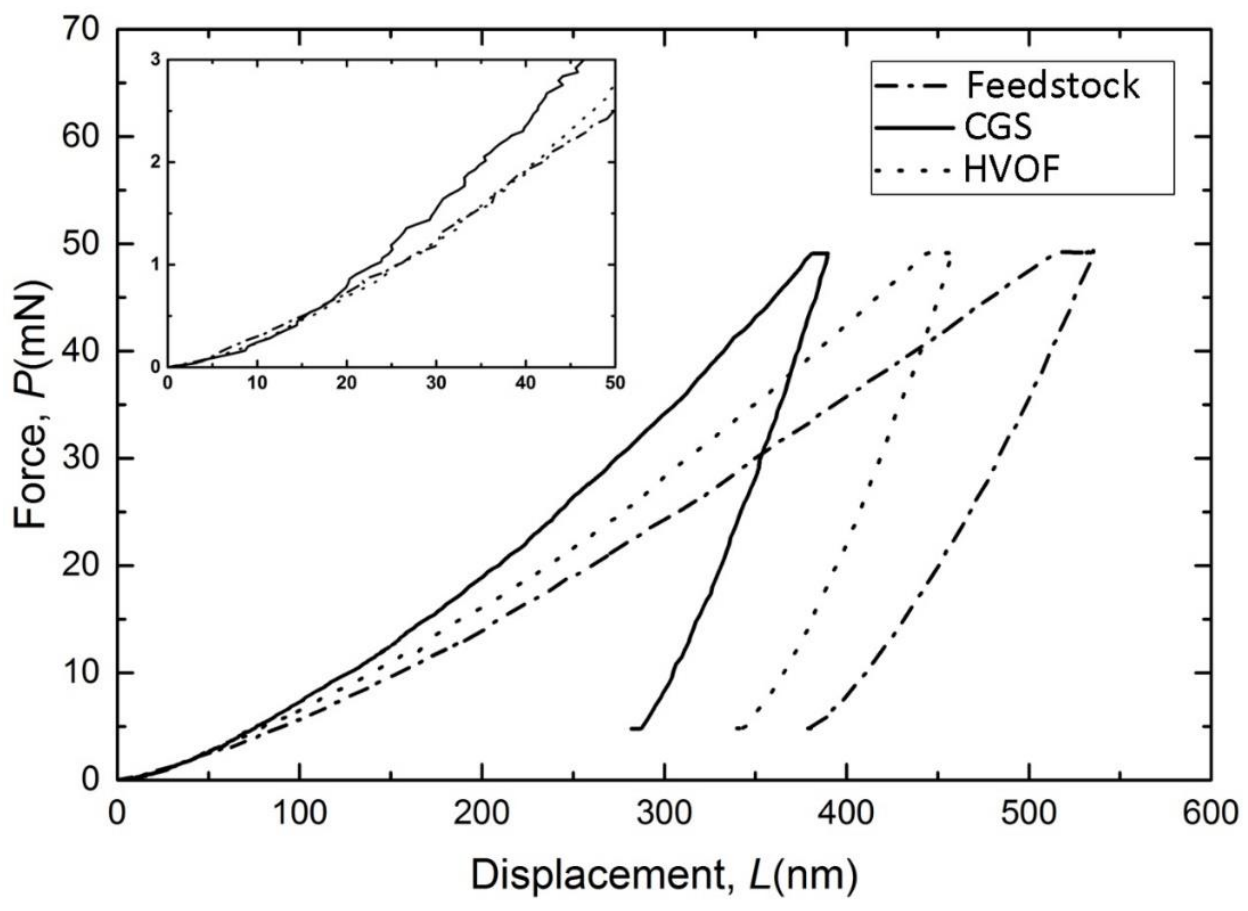



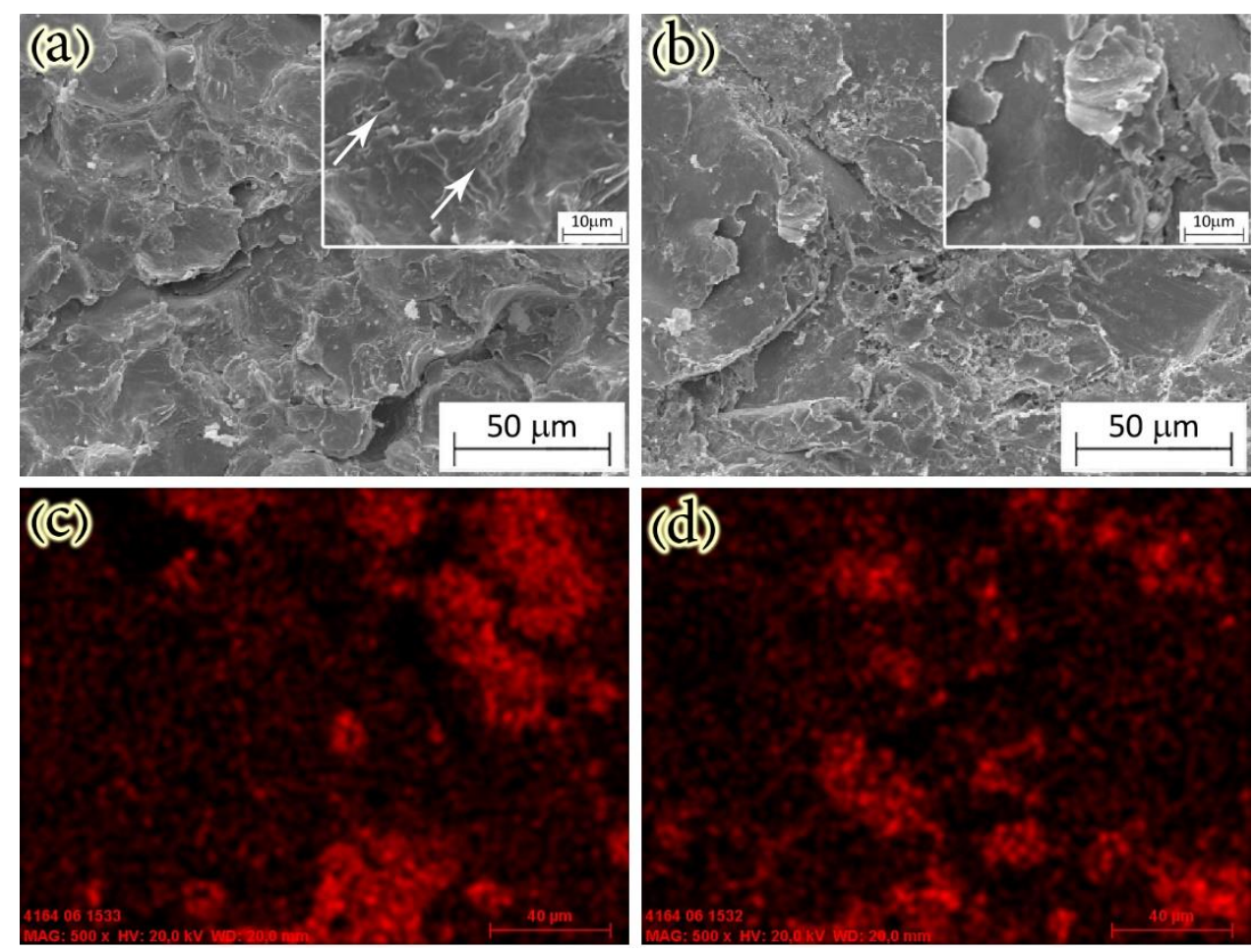

(d)

8 


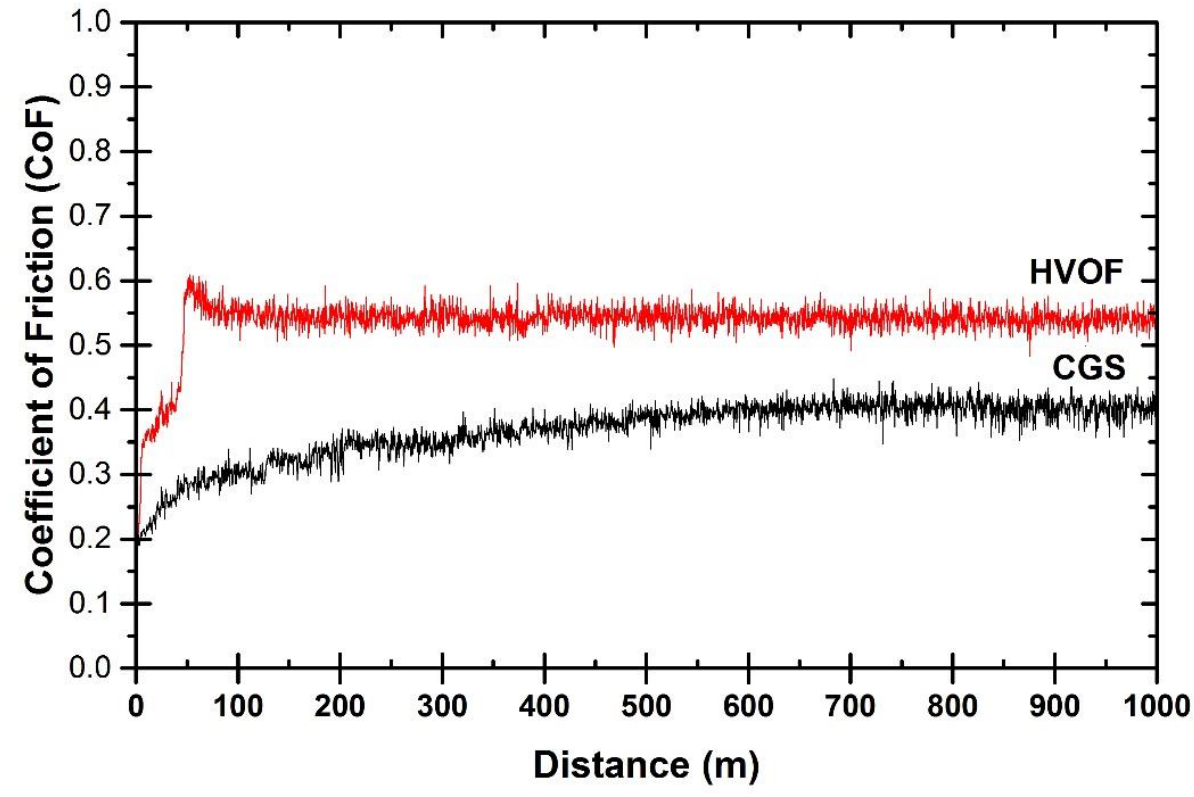


(a)

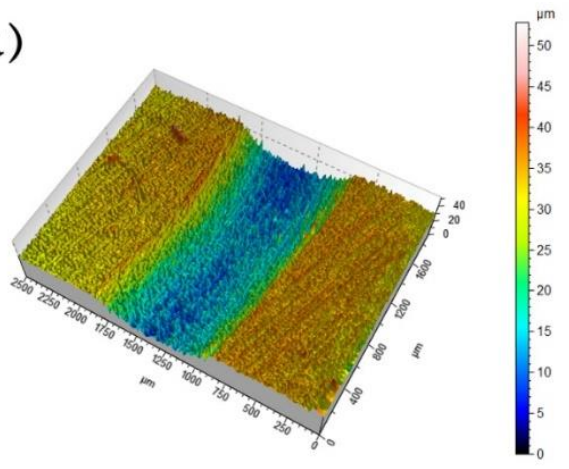

(C)

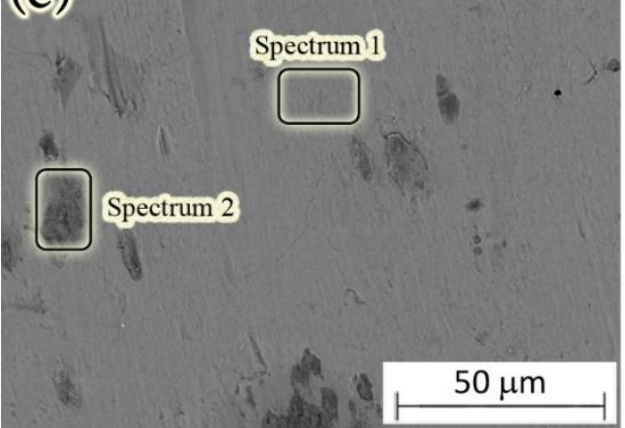

(e)

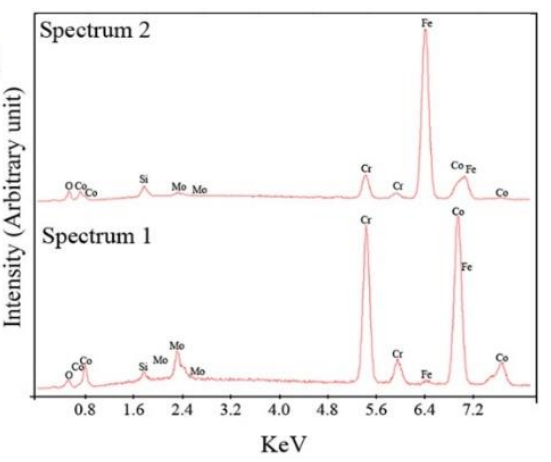

(b)
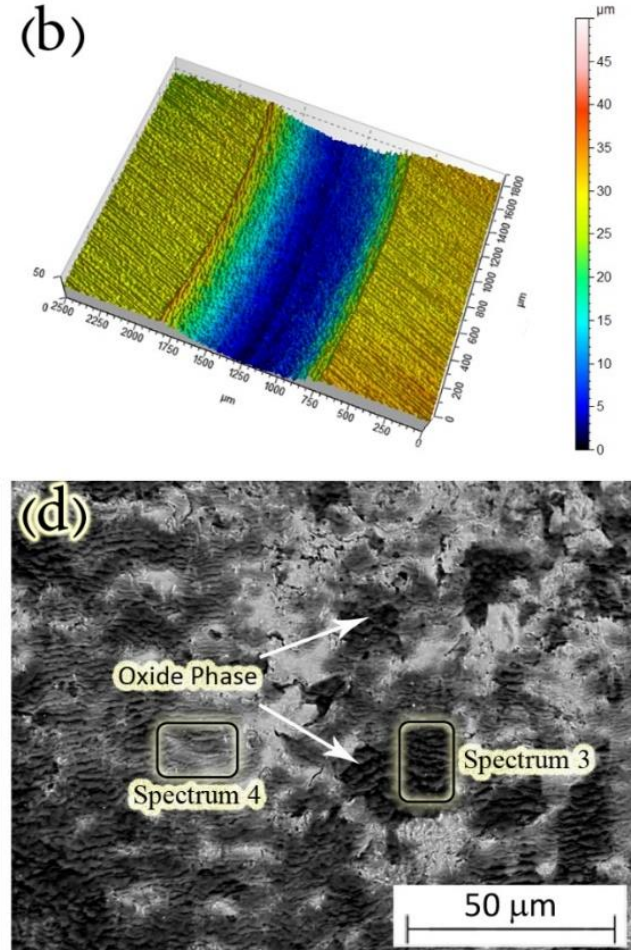

(f)

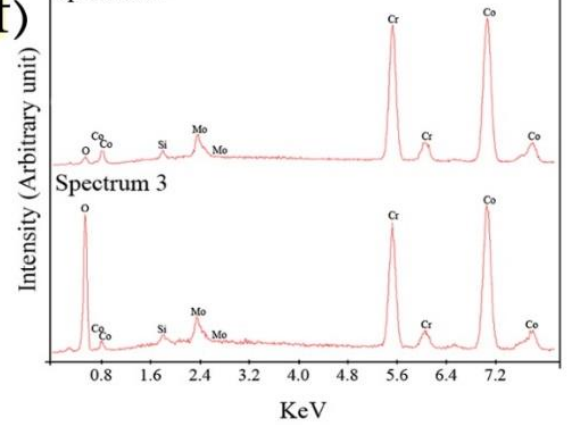

10 

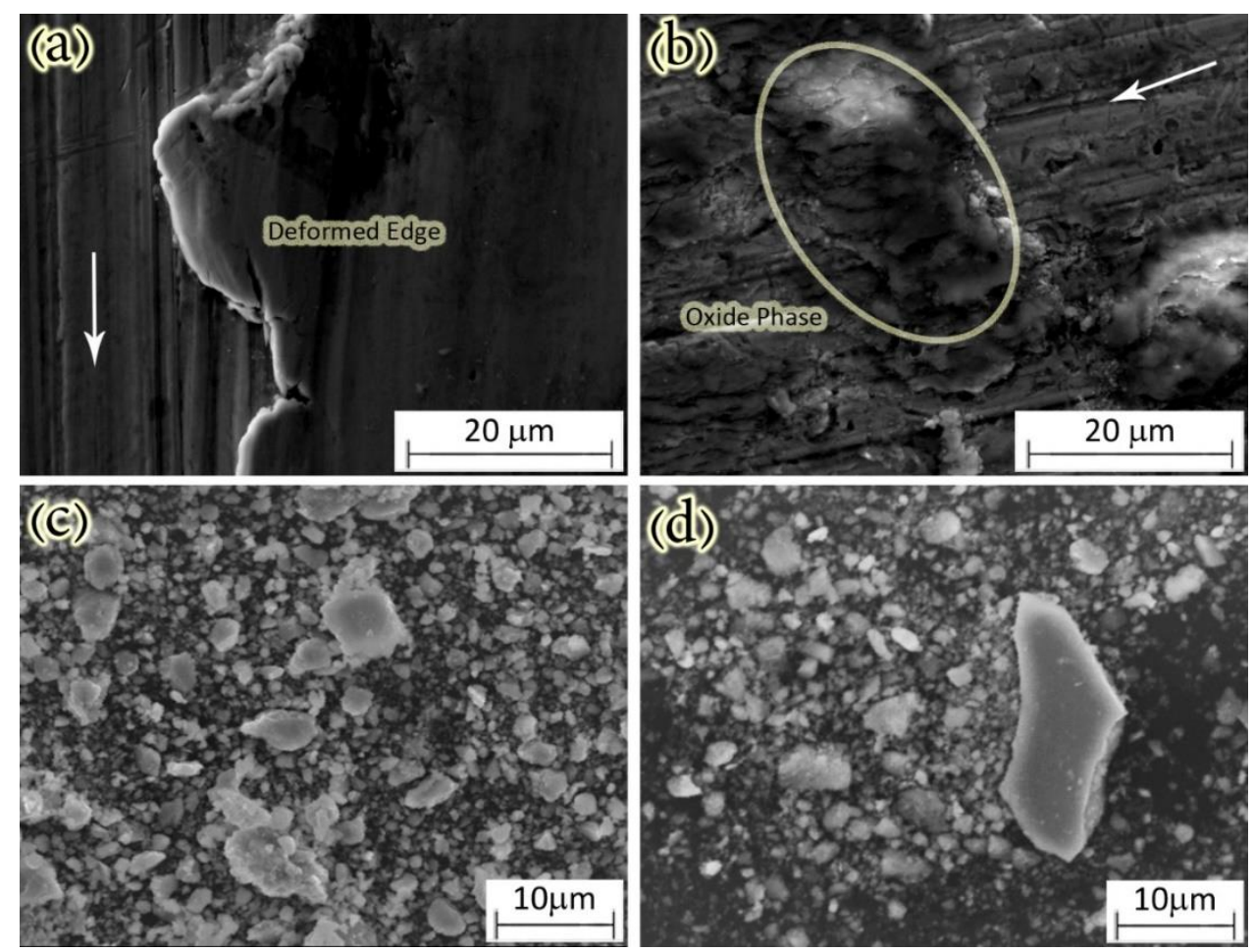

11 


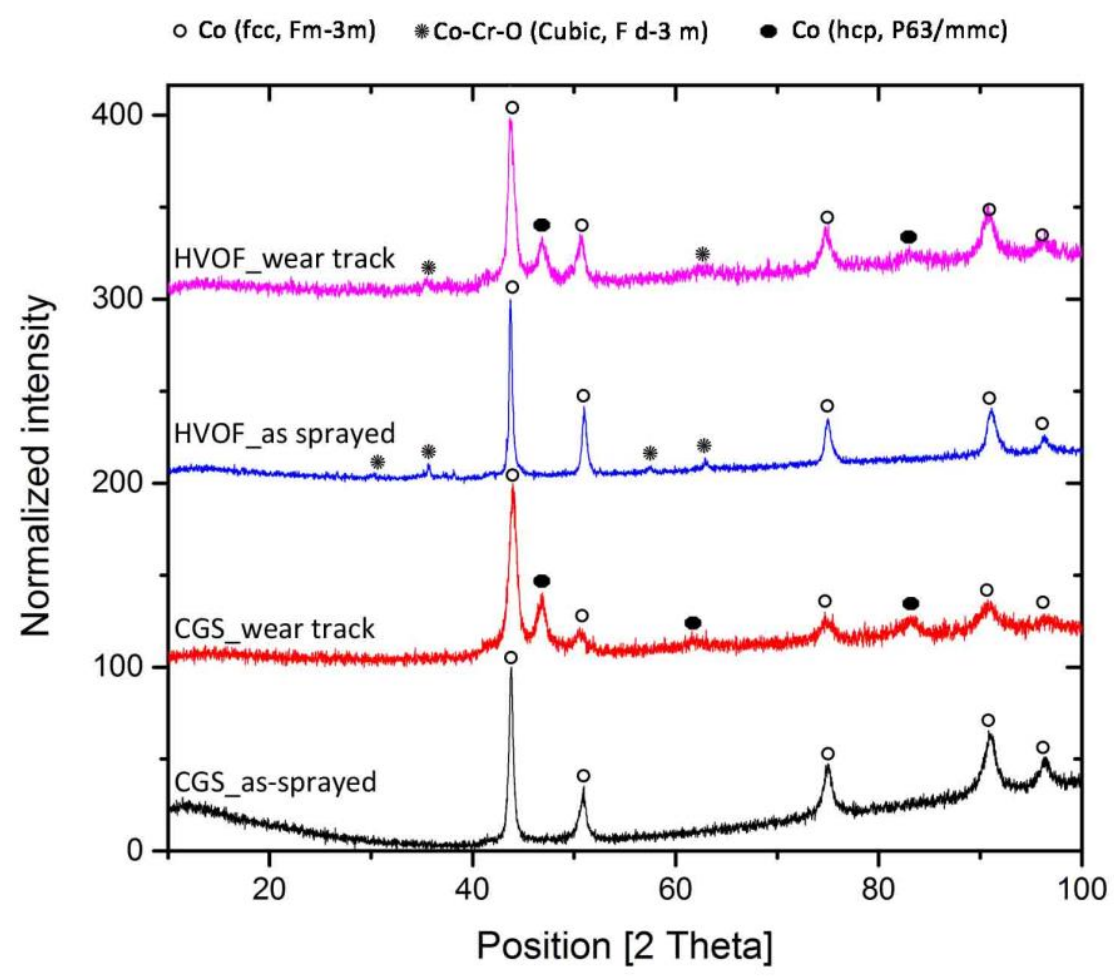

12 

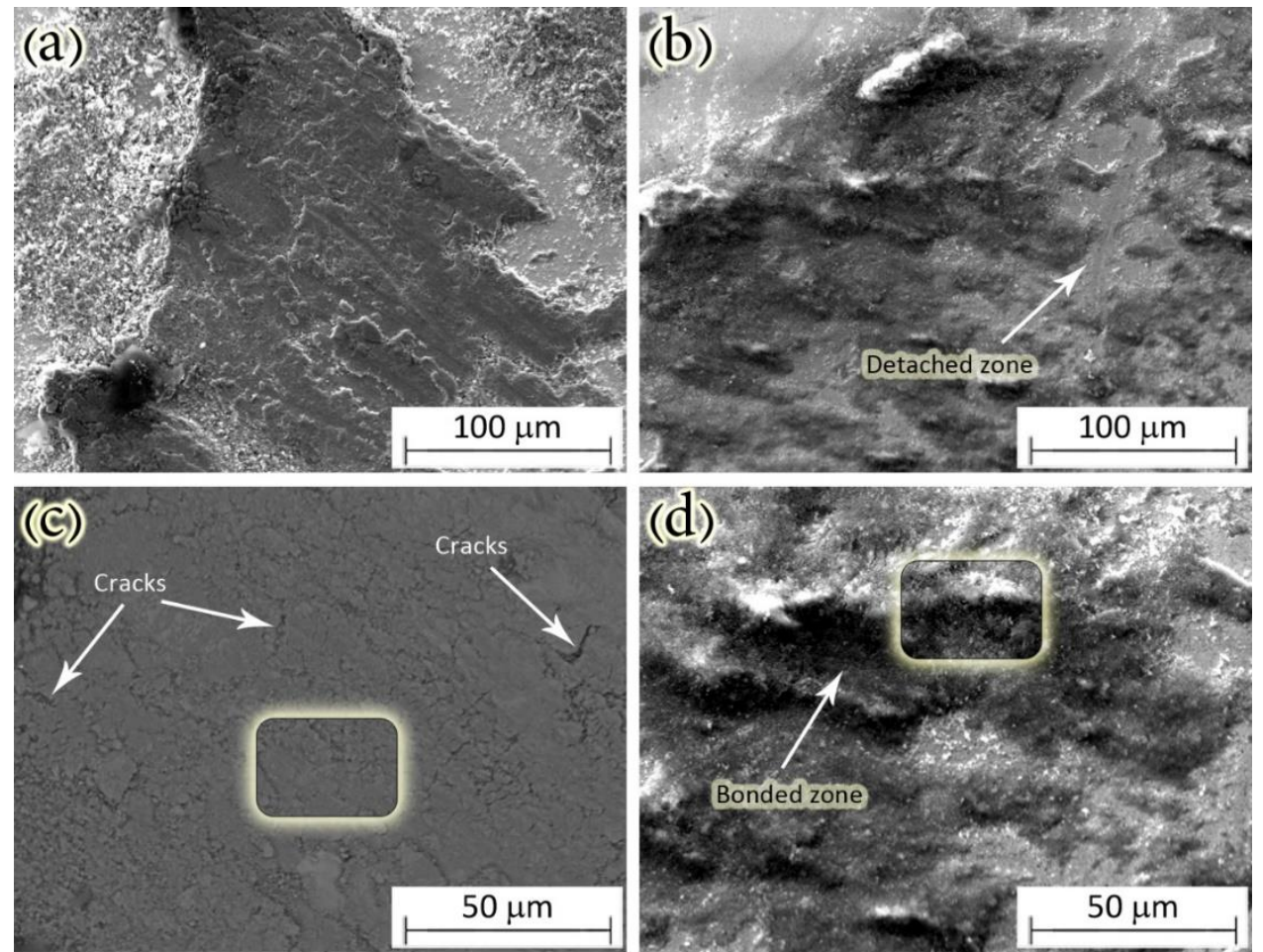

(e)
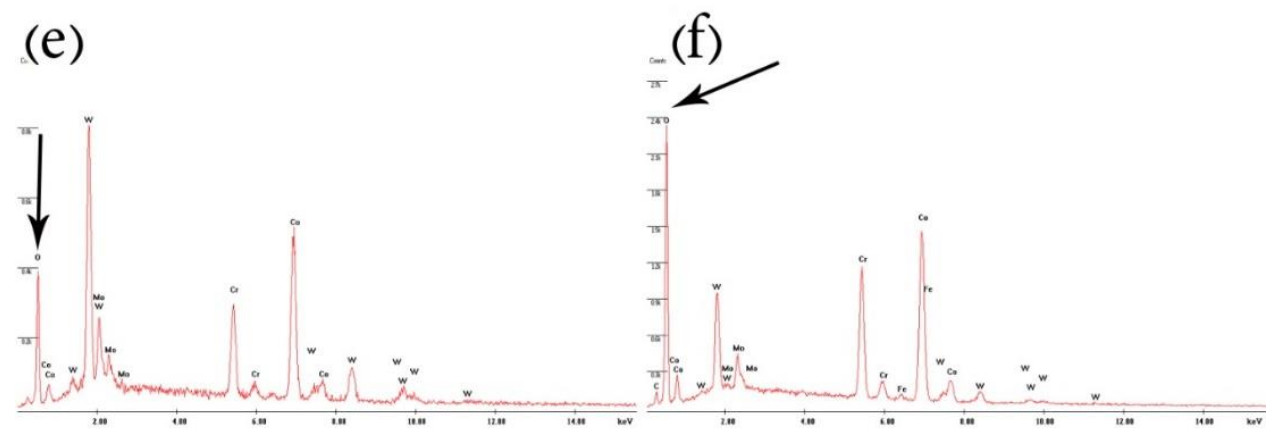

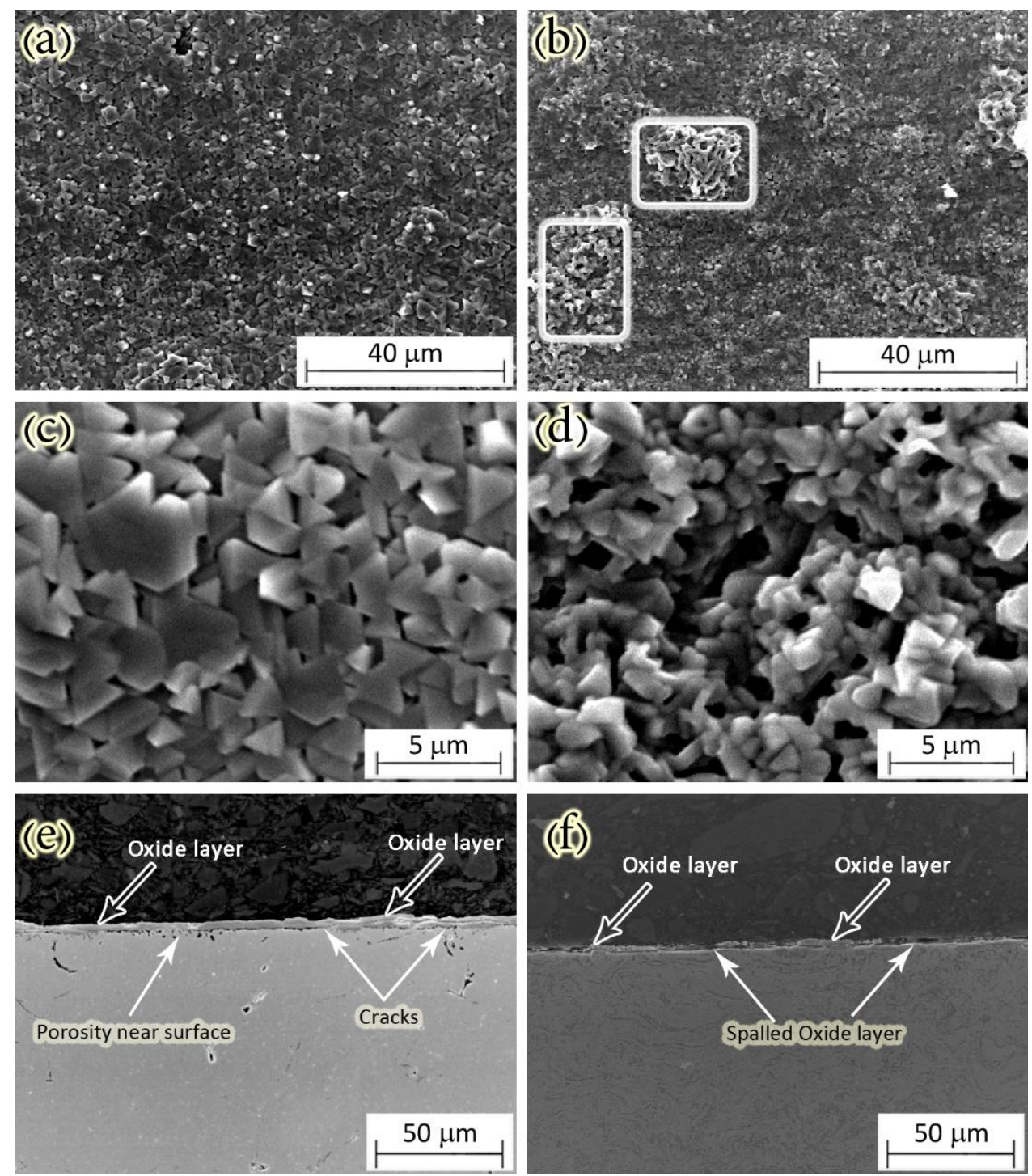

14 


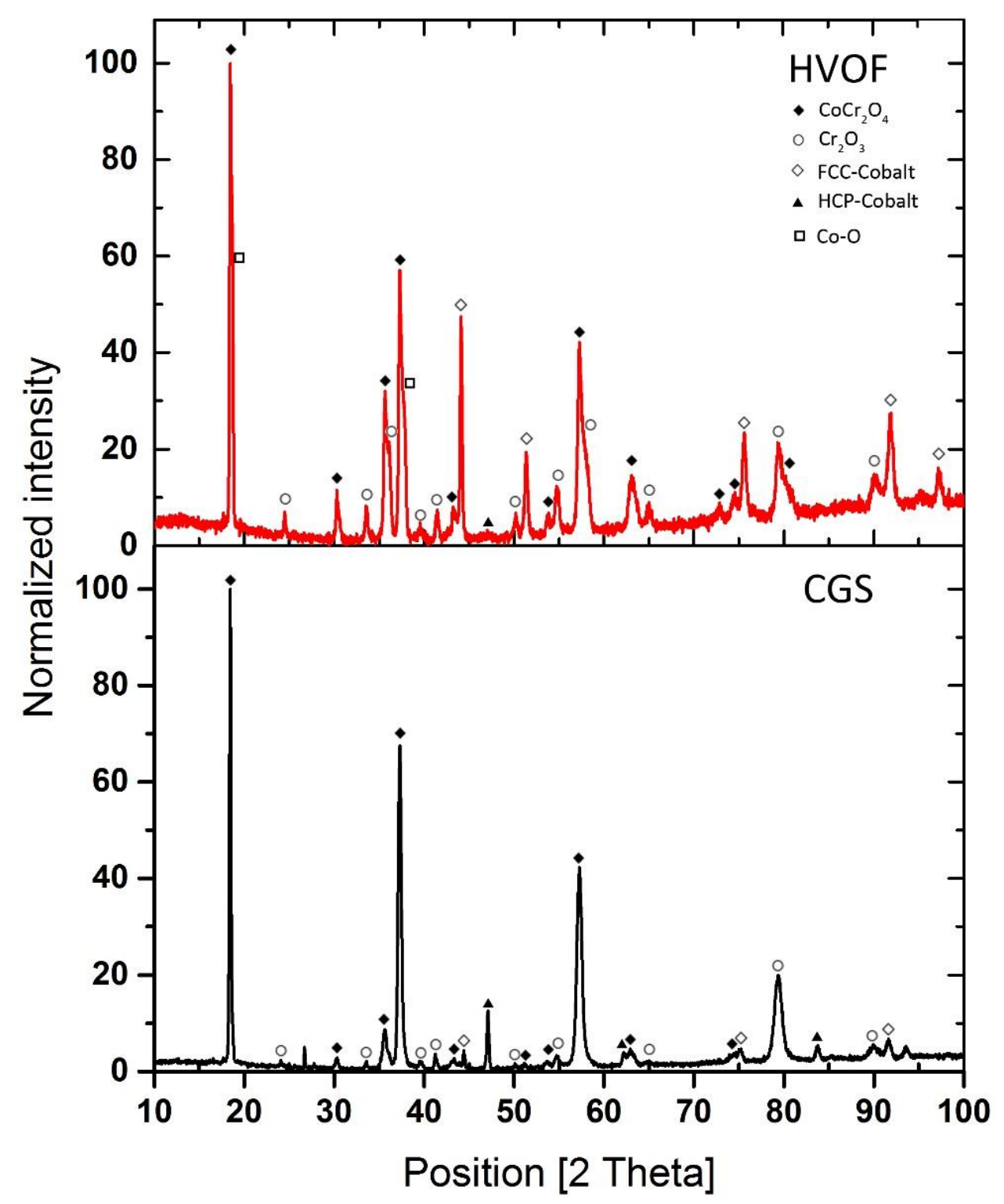

15 